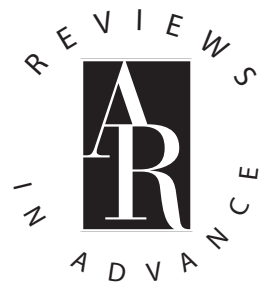

Review in Advance first posted online on January 3, 2013. (Changes may still occur before final publication online and in print.)

\title{
Metabolic Regulation of T Lymphocytes
}

\author{
Nancie J. MacIver, ${ }^{1}$ Ryan D. Michalek, ${ }^{2}$ \\ and Jeffrey C. Rathmell ${ }^{2,3,4}$
}

\begin{abstract}
${ }^{1}$ Department of Pediatrics, ${ }^{2}$ Department of Pharmacology and Cancer Biology,
${ }^{3}$ Department of Immunology, ${ }^{4}$ Sarah W. Stedman Nutrition and Metabolism Center, Duke University Medical Center, Durham, North Carolina 27710; email: jeff.rathmell@duke.edu
\end{abstract}

Annu. Rev. Immunol. 2013. 31:259-83

The Annual Review of Immunology is online at immunol.annualreviews.org

This article's doi:

10.1146/annurev-immunol-032712-095956

Copyright (c) 2013 by Annual Reviews.

All rights reserved

\section{Keywords}

T cell, glucose, oxidative phosphorylation, aerobic glycolysis, Glut1

\begin{abstract}
T cell activation leads to dramatic shifts in cell metabolism to protect against pathogens and to orchestrate the action of other immune cells. Quiescent T cells require predominantly ATP-generating processes, whereas proliferating effector $\mathrm{T}$ cells require high metabolic flux through growth-promoting pathways. Further, functionally distinct $T$ cell subsets require distinct energetic and biosynthetic pathways to support their specific functional needs. Pathways that control immune cell function and metabolism are intimately linked, and changes in cell metabolism at both the cell and system levels have been shown to enhance or suppress specific $\mathrm{T}$ cell functions. As a result of these findings, cell metabolism is now appreciated as a key regulator of $\mathrm{T}$ cell function specification and fate. This review discusses the role of cellular metabolism in T cell development, activation, differentiation, and function to highlight the clinical relevance and opportunities for therapeutic interventions that may be used to disrupt immune pathogenesis.
\end{abstract}


Glycolysis: metabolic program in which glucose-derived pyruvate is converted to lactate, producing $\mathrm{CO}_{2}$ and two molecules of ATP for every one molecule of glucose; does not require the presence of oxygen

Aerobic glycolysis: metabolic program in which glycolytic flux is high and lactate is produced from glucose-derived pyruvate, despite the presence of sufficient oxygen

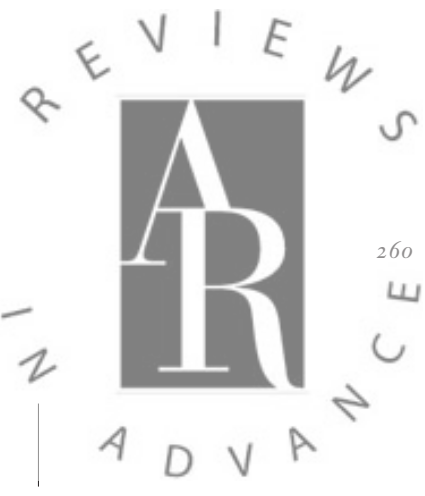

\section{INTRODUCTION}

One of the most fundamental cellular requirements is the ability to access sufficient and appropriate nutrients to support essential cellular functions. As cells are stimulated to grow, proliferate, or die, their metabolic requirements change, and it is important that cellular metabolism matches these demands. Although immune cells spend a significant amount of time in blood, where nutrients are generally abundant, the manner in which these cells uptake and utilize nutrients remains of fundamental importance. We now understand that the regulation of nutrient uptake and utilization is critically important for the control of immune cell number and function. Furthermore, the pathways that control immune cell function and metabolism are intimately linked. These associations and newly found coordination between the immune system and classical metabolic tissues now provide new opportunities to impact immune function in both healthy and diseased states.

The study of cellular metabolism and the manner in which metabolism can change in proliferative tissues and cells has a rich history. In a seminal finding nearly a century ago, Otto Warburg (1) first observed that rather than relying on mitochondrial oxidative pathways for maximal energy generation, cancer cells use the less efficient process of glycolysis, producing lactic acid even in the presence of sufficient oxygen (2). Interestingly, Warburg was also one of the first to study leukocyte metabolism and found the same to be true of activated leukocytes: Resting leukocytes use primarily an aerobic oxidative metabolism, whereas stimulation leads to a shift toward glycolysis as the primary metabolic program (3). These findings were contrary to classical biochemistry of the time for mammalian cells, as it was believed that cells would rely on the conversion of pyruvate to lactate only when mitochondria were damaged or if oxygen was not present. As these cells used glycolysis even in the presence of oxygen, this metabolic program was termed aerobic glycolysis.
The similarity of cancer cell and activated lymphocyte metabolism is not coincidental and begins to explain why cells may choose aerobic glycolysis over more energy-efficient mitochondrial oxidative pathways. In the end, metabolism must match cell functional demands, and both cancer cells and stimulated lymphocytes are signaled to grow and rapidly proliferate. They share, therefore, a metabolic demand to prioritize efficient and rapid biosynthesis over efficient energy/ATP production. The shift from oxidative metabolism to glycolysis is perfectly suited to match this shift in metabolic demand, as oxidative metabolism funnels glucose-derived pyruvate to the mitochondria for oxidation potentially down to carbon dioxide, and glycolysis produces many intermediates that can be used for biosynthesis (Figure 1). In addition to increased glycolysis, some glucose transitions through the mitochondria and a portion of the tricarboxylic acid (TCA) cycle to generate citrate for lipid synthesis. To allow continued TCA flux as citrate molecules are removed to produce lipid membranes, glutamine oxidation increases in a process of anapleurosis that can provide $\alpha$-ketoglutarate for the TCA cycle and metabolic intermediates for biosynthesis of a variety of macromolecules. Thus, although aerobic glycolysis is best characterized by increased rates of glycolysis, coordinated action of glycolysis and mitochondrial metabolism is essential.

The molecular details of how $\mathrm{T}$ cell metabolism is regulated, and how changes in metabolism impact cell function, are now becoming apparent. In particular, resting $\mathrm{T}$ cells appear to oxidize glucose-derived pyruvate along with lipids and amino acids. Upon activation, glycolysis increases along with glutamine oxidation. Lipid oxidation, however, decreases sharply, and lipid synthesis rather than oxidation is favored. At the end of an immune response, most cells die. The cells that survive to become memory cells, however, revert back to lipid oxidation and an increased capacity for efficient energy generation.

Both maintenance of basal oxidative metabolism in the resting cell and the transition 
Resting or memory

lymphocyte
Activated

lymphocyte

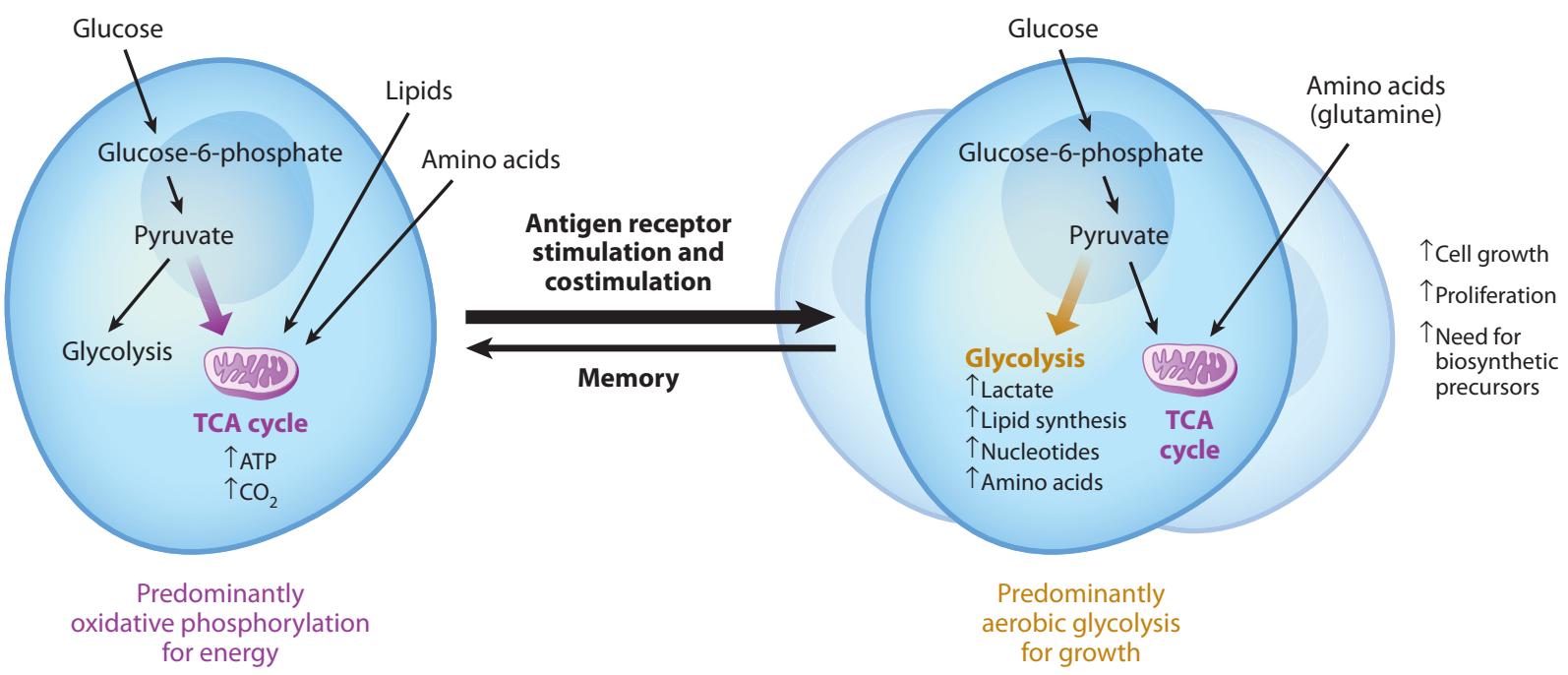

Figure 1

T cell metabolic programs match functional demands. Resting $\mathrm{T}$ cells oxidize glucose-derived pyruvate, along with lipids and amino acids, to efficiently produce ATP/energy required for immune surveillance. Upon activation, lipid oxidation is downregulated, and glycolysis increases along with glutamine oxidation, in order to produce biosynthetic precursors required for rapid cell growth and proliferation. At the end of an immune response, the cells that survive to become memory $\mathrm{T}$ cells revert back to lipid oxidation with increased capacity for efficient energy generation.

to glutamine and glucose uptake and aerobic glycolysis in activated $\mathrm{T}$ cells are highly regulated processes that are controlled both transcriptionally and posttranscriptionally. These intracellular processes are regulated by specific extracellular signals that shape cell metabolism so that activated lymphocytes are metabolically distinct from resting cells and have the appropriate nutrient input to meet their functional demands. Even lymphocyte subsets show metabolic distinctions that may reflect specific functional needs. Our current understanding of these metabolic processes in lymphocytes is discussed in this review, with consideration given to the clinical relevance of lymphocyte metabolism in states of differentiation, immune dysregulation, and nutritional disorders.

\section{THYMOCYTE METABOLISM AND NOTCH}

Lymphocyte development is highly regulated and involves multiple proliferative and selection events prior to the emergence of naive resting T cells from the thymus. Upon arrival from the bone marrow, double-negative (DN) thymocytes initiate $\mathrm{V}(\mathrm{D}) \mathrm{J}$ rearrangement to generate antigen receptors. If a $\mathrm{T}$ cell receptor (TCR) $\beta$ chain is successfully rearranged, DN cells undergo $\beta$-selection and transition through the DN3 and DN4 phases of thymic development. This particular selection event then leads to significant proliferation. Interestingly, the glucose transporter Glut1 is specifically induced at this stage and may indicate an increase in glycolysis $(4,5)$. Glut1 is then downregulated as cells mature to more quiescent $\mathrm{CD} 4^{+} \mathrm{CD}^{+}$doublepositive (DP) or $\mathrm{CD}_{4}^{+} \mathrm{CD}^{-}$and $\mathrm{CD}^{-}{ }^{-} \mathrm{CD} 8^{+}$ single-positive (SP) cells.

Multiple signaling pathways are essential in early thymic differentiation, and the Notch signaling pathway plays a key role in regulating metabolism. Upon ligation, Notch undergoes proteolytic cleavage that results in release of an intracellular domain of the Notch receptor
T cell receptor (TCR): recognizes antigen presented by an MHC molecule on an adjacent cell and, via complex with $\mathrm{CD} 3$ signaling molecules, provides the first signal in $T$ cell activation

Glut1: ubiquitously expressed glucose transporter that is critical for hematopoietic cell glucose uptake

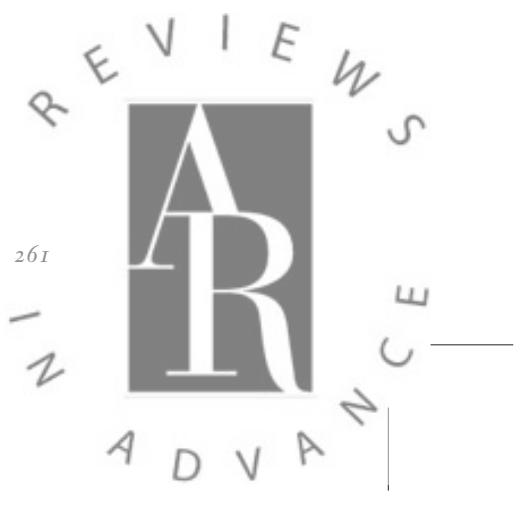


Notch1:

transmembrane protein with intracellular signaling that regulates thymocyte development and promotes glucose metabolism

PI3K: family of intracellular enzymes able to phosphorylate the 3-position hydroxyl group of the inositol ring of phosphatidylinositol, resulting in phosphatidylinositol 3-phosphate, which can recruit, bind, and activate Akt

Akt: serine threonine kinase recruited to the cell membrane by phosphatidylinositol 3-phosphate; once phosphorylated by PDK1 and the mTORC2 complex, Akt promotes aerobic glycolysis and cell survival and activates the mTOR pathway

$\beta$-oxidation: mitochondrial oxidative pathway that catabolizes lipids to generate FADH2, $\mathrm{NADH}$, and acetyl-CoA and allows production of up to 106 ATP per palmitate molecule

IL-7:

cytokine/interleukin that is critically important in $\mathrm{T}$ cell survival and plays a $\checkmark$ ple in reg tiating glucose metabolisina

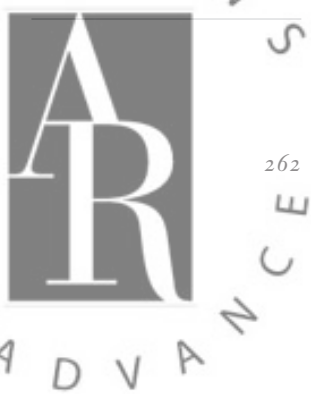

(ICN), which serves as a transcriptional regulator that can promote a variety of developmental fate decisions (6). Similar to its role in developmental fate, Notch has an essential role in early $\mathrm{T}$ cell development. Mice with an inducible knockout of Notch1 during the neonatal period had a severe deficiency of thymocyte development, with developmental arrest of the most immature stage $\left(\mathrm{CD} 44^{+} \mathrm{CD} 25^{-}\right)$thymocytes (7). In contrast, expression of constitutively active Notch 1 in hematopoietic stem cells resulted in an ectopic outgrowth of immature $\mathrm{CD}^{+}{ }^{+} \mathrm{CD} 8{ }^{+} \mathrm{DP} T$ cells in the bone marrow (8).

In addition to promoting hematopoietic stem cell differentiation toward the $\mathrm{T}$ cell lineage, Notch signaling is critical in $\beta$-selection of DN thymocytes (9). DN thymocytes atrophied when deprived of Notch signals, with lower Glut1 expression and decreased glycolytic rate, eventually leading to apoptotic death. The mechanism by which Notch signaling promotes thymocyte glucose metabolism is not entirely clear, but Notch can lead to activation of the phosphatidylinositol 3-kinase (PI3K)/Akt signaling pathway, which is well established to drive glucose metabolism and aerobic glycolysis in a variety of systems (10). Inhibition of PI3K or Akt in DN thymocytes suppressed glucose metabolism, whereas overexpression of a myristoylated and constitutively active Akt1 (Myr-Akt) restored glucose metabolism in Notch-deprived thymocytes (9). Importantly, this overcame the block in early pre-T cell development observed upon disruption of Notch signaling.

\section{RESTING T CELLS}

Upon exit from the thymus, mature resting $\mathrm{T}$ cells have low metabolic requirements that serve to fuel basal energy generation and replacement biosynthesis. Naive resting $\mathrm{T}$ cells are not precisely resting but rather continually migrating through secondary lymphoid tissues on immune surveillance prior to activation. Thus, cytoskeletal rearrangements occur constantly. This process is ATP expensive but requires only basal replacement biosynthesis.
Resting T cells, therefore, have a metabolic balance that favors energy production over biosynthesis. To accommodate this need, resting $\mathrm{T}$ cells rely predominantly on the high-energyyielding processes of fatty acid $\beta$-oxidation and pyruvate and glutamine oxidation via the TCA cycle. But even resting $\mathrm{T}$ cells require cellextrinsic signals to maintain this basal energygenerating metabolism. If $\mathrm{T}$ cells are removed from their normal microenvironment, they internalize and degrade Glut1 as well as other nutrient transporters, thus preventing sufficient nutrient uptake to maintain viability. Both the IL-7 receptor (IL-7R) and TCR are important in this process.

\section{IL-7}

IL-7 is critically important for T cell growth and survival. It is a prosurvival factor for early thymocytes, resting peripheral naive $\mathrm{T}$ cells, and memory $\mathrm{T}$ cells. Indeed, defects in this pathway are a cause of severe combined immunodeficiency in humans and mice. IL-7R signaling through the unique IL-7R $\alpha$ and the common $\gamma$ chain $\left(\gamma_{c}\right)$ leads to activation of the Janus kinase JAK3 and phosphorylation of signal transducer and activator of transcription-5 (STAT5) as well as a more delayed activation of the PI3K/Akt signaling pathway $(11,12)$. IL-7 is essential for naive T cell survival (13), and induction of $\mathrm{Bcl}-2$, in particular, plays an important role. Consistent with this role, the expression of a T cell-specific Bcl-2 transgene to inhibit apoptosis was sufficient to rescue the development and survival of IL-7R-deficient T cells $(14,15)$. Nevertheless, T cell numbers and function were not completely rescued by Bcl-2, indicating an additional role for IL-7 and the IL-7R beyond simply preventing cell death.

One alternative role for the IL-7R is regulation of basal glucose and amino acid metabolism to meet the needs of quiescent $\mathrm{T}$ cells. Normally, $\mathrm{T}$ cells that fail to receive normal microenvironmental cues undergo cellular atrophy, with decreased cell size and metabolism that ultimately lead to apoptosis (16). IL-7 is expressed by stromal cells in T cell zones and 
plays a key role in preventing atrophy and maintaining resting $\mathrm{T}$ cell metabolism. Culture of naive $T$ cells in recombinant IL-7 can partially maintain cell size, glucose uptake, and glycolysis. These changes are linked to the prosurvival effects of IL-7, as glucose deprivation inhibits IL-7-mediated cell survival despite Bcl2 induction (11). The IL-7R regulates glucose uptake largely through the PI3K/Akt/mTOR pathway, which can promote cell surface trafficking of Glut1 $(11,17,18)$. This regulation of glycolysis by the IL-7R is critical for basal $T$ cell metabolism in vivo, as conditional deletion of the IL-7 R in mature $T$ cells in vivo leads to cellular atrophy and an inability to maintain glycolysis (19). In addition to metabolizing glucose, resting $\mathrm{T}$ cells oxidize amino acids, and recent studies indicate that IL-7-induced growth of $\mathrm{CD}^{+} \mathrm{T}$ cells is dependent on amino acids and that amino acid transporters are specific targets of IL-7 signaling (20), implying a broad role for IL-7 in resting $\mathrm{T}$ cell metabolism.

\section{Antigen Receptor}

The TCR also provides a signal to maintain cell homeostasis in the naive $T$ cell population (21, $22)$. In the absence of TCR signal, Glut1 expression decreases, thus limiting glucose uptake and subsequent baseline ATP production and biosynthetic capacity, which leads to metabolic stress and apoptosis $(11,16,23)$. Similarly, antigen receptor in B cells is also required to maintain glucose metabolism via PI3K (24). The manner in which antigen receptor stimulation maintains baseline Glut1 expression in lymphocytes is not completely understood; however, in activation, TCR signaling is sufficient to upregulate Glut1 expression (10), and similar signaling pathways likely exist in resting cells.

\section{T CELL ACTIVATION}

Stimulated T cells must rapidly grow, divide, and exert effector function. As a result, the metabolic requirements of $T$ cells increase dramatically upon activation, to support biosynthesis of intracellular constituents including lipid membranes, nucleic acids, and proteins. $T$ cells meet this demand and maintain sufficient intermediate metabolites for cell growth by simultaneously increasing glucose and glutamine metabolism while decreasing lipid oxidation (Figure 1). Studies on peripheral blood leukocytes, which were first performed by Otto Warburg, showed that glycolysis and lactate production, in particular, are strongly increased upon mitogenic stimulation (3). More recent studies have found the same for mitogen-activated thymocytes (25) and peripheral $\mathrm{T}$ cells (26). In a more physiologic system, immunization leads to a rapid increase in Glut1 expression, indicating an increase in glucose uptake and metabolism during acute in vivo $T$ cell stimulation (27). Importantly, these metabolic changes strongly contribute to and are essential for proper $\mathrm{T}$ cell function. Excessively increased glucose uptake in $\mathrm{T}$ cells with transgenic expression of Glut1 can lead to increased cytokine production and proliferation and, ultimately, to lymphoproliferative disease (23, 27). Conversely, inadequate nutrients or direct metabolic inhibition prevents $\mathrm{T}$ cell activation and proliferation $(23,28)$. If prolonged, this can lead to T cell anergy (29) or cell death. Consistent with a metabolic requirement or checkpoint in effector $\mathrm{T}$ cell (Teff) proliferation and function, the glycolytic inhibitor 2deoxyglucose (2DG) can protect animals from experimental autoimmune encephalomyelitis (EAE) (30). The metabolic program of activated $\mathrm{T}$ cells is regulated at both the transcriptional and posttranscriptional levels (Table 1). Given the similar metabolic demands and glycolytic programs of cancer cells and activated T cells, it is not surprising that regulatory mechanisms to promote aerobic glycolysis are shared between these otherwise diverse cell types.

\section{TRANSCRIPTIONAL REGULATORS OF METABOLISM}

\section{c-Myc}

The oncogenic transcription factor c-Myc contributes to a wide variety of human cancers and
Bcl-2 proteins:

family of apoptosis-regulating proteins; members can be pro- or antiapoptotic

Mammalian target of rapamycin (mTOR): serine/threonine kinase that integrates nutrient and energy status to regulate cell survival, growth, and proliferation through the mTORC1 and mTORC2 protein complexes

Anergy: state of T cell hyporesponsiveness that results from TCR stimulation in the absence of costimulation or secondary signals

c-Myc: transcription factor involved in many cancers and critically important for cellular cycling and metabolism; required for upregulation of both glucose and glutamine metabolism in $\mathrm{T}$ cell activation

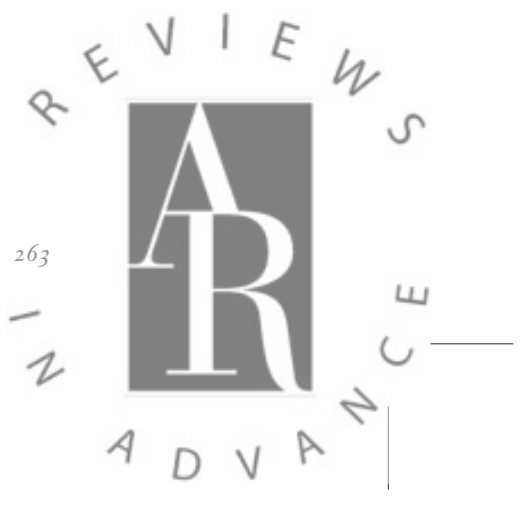


Table 1 Role of transcriptional and posttranscriptional regulators of $\mathrm{T}$ cell metabolism ${ }^{\mathrm{a}}$

\begin{tabular}{l|l}
\hline $\begin{array}{l}\text { Transcriptional regulators } \\
\begin{array}{l}\text { Notch: promotes glucose metabolism during T cell } \\
\text { development }\end{array}\end{array}$ & PI3K/Akt: $\uparrow$ Glutl surface expression \\
\hline $\begin{array}{l}\text { c-Myc: } \uparrow \text { glycolysis, } \uparrow \text { glutamine metabolism, } \uparrow \text { cell } \\
\text { cycle genes }\end{array}$ & $\begin{array}{l}\text { mTOR: } \uparrow \text { Glut1 surface expression, promotes } \\
\text { effector T cells }\end{array}$ \\
\hline $\begin{array}{l}\text { ERRa: } \uparrow \text { mitochondrial oxidation } \\
\text { LXR: } \downarrow \text { T cell activation, } \uparrow \text { cholesterol and lipid } \\
\text { efflux }\end{array}$ & \begin{tabular}{l} 
ERK: $\uparrow$ glutamine uptake \\
\hline $\begin{array}{l}\text { HIF-1a: } \uparrow \text { glycolytic genes, promotes Th17 } \\
\text { generation }\end{array}$
\end{tabular} \\
\hline
\end{tabular}

aThe metabolic program of activated T cells is regulated at both the transcriptional and posttranscriptional levels. Several key regulators are highlighted. $\uparrow=$ upregulate; $\downarrow=$ downregulate.

regulates many genes instrumental in both the cell cycle and metabolism. Among the processes regulated by c-Myc are glucose and glutamine metabolism and mitochondrial biogenesis. Specifically, c-Myc can direct the expression of all the glycolytic genes, including Glut1, lactate dehydrogenase A (LDHA), PKM2, and hexokinase 2 (31), as well as glutaminase and the glutamine transporters SLC3a2, SLC5A1, and SLC7A1 $(32,33)$. In $\mathrm{T}$ cells, c-Myc is induced upon activation and promotes $\mathrm{T}$ cell growth and entry into the cell cycle (34-36). Recently, a role for c-Myc in T cell metabolism was found using an in silico approach to identify transcription factors whose gene targets correlated with changes in metabolic gene expression upon T cell stimulation (36). Subsequently, the acute genetic deletion of c-Myc in mature $\mathrm{T}$ cells inhibited the upregulation of glycolytic and glutaminolytic gene expression in stimulated $\mathrm{T}$ cells that correlated with a failure of c-Myc-deficient cells to proliferate. Importantly, the inability of c-Myc-deficient T cells to upregulate metabolic gene expression was evident early after activation, at a time prior to entry of $\mathrm{T}$ cells into the cell cycle. Thus, although it was not possible to fully exclude secondary effects of altered proliferation, c-Myc deficiency appeared to directly regulate T cell metabolism.

The metabolic role for c-Myc in T cells is quite broad. In addition to driving expression of the entire program of glycolysis, c-Myc is essential for T cells to upregulate glutaminolysis to generate $\alpha$-ketoglutarate (36). This pathway may be particularly important in aerobic glycolysis to feed the TCA cycle in a process termed anapleurosis; it also allows continued flux of glucose-derived citrate to leave the mitochondria and be used in lipid synthesis. In addition, $\alpha$-ketoglutarate can provide a precursor for polyamine synthesis, which may be important in DNA synthesis and replication. Glutaminase is critical for glutamine metabolism, and c-Myc is essential to induce glutaminase 2 (Gls2) $(36,37)$. Gls1 is also a c-Myc target, can be induced at later time points, and, as shown by RNAi, is essential for $\mathrm{T}$ cell proliferation (37). These data match findings in cancer, in which c-Myc promotes glycolysis and glutaminolysis while rendering cells highly dependent on glutaminolysis for growth and survival (38). Glutaminase inhibitors, therefore, are of interest in cancer and are likely also immunosuppressive.

\section{Nuclear Hormone Receptors in T Cell Metabolism}

The increased glucose metabolism of activated $\mathrm{T}$ cells requires the coordination of multiple transcriptional programs to simultaneously increase glycolysis, glutaminolysis, and lipid and cholesterol synthesis, while preventing 
lipid oxidation and sterol efflux. Despite the critical role for $\mathrm{c}-\mathrm{Myc}$ in glucose and glutamine metabolism, mitochondrial pathways, such as the TCA cycle and electron transport, were not strongly affected by c-Myc deficiency in $\mathrm{T}$ cell activation (36). Changes in lipid metabolism were likewise not entirely reliant on c-Myc (36). Thus, additional transcriptional mechanisms must be employed to induce the mitochondrial biogenesis and upregulation of genes required for the TCA cycle and electron transport as well as lipid synthesis. A number of additional transcriptional mediators, including several nuclear hormone receptors, have been recently identified to regulate these aspects of T cell metabolism.

The estrogen-related receptors (ERR $\alpha, \beta$, and $\gamma ; \mathrm{NR} 3 \mathrm{~B} 1,2$, and 3 , respectively) are a subfamily of nuclear receptors with established roles in regulating both glycolytic and mitochondrial metabolic pathways $(39,40)$. These orphan receptors have homology to estrogen receptors and are thought to have constitutive transcriptional activity that is regulated by cofactor interactions with transcription factors such as $\mathrm{PGC} 1 \alpha / \beta$ (peroxisome proliferatoractivated receptor gamma coactivator 1 ) and deacetylation by Sirt1 (sirtuin 1) (41). Expression of $\operatorname{ERR} \beta$ is not well characterized in the immune system, but $\mathrm{ERR} \alpha$ is ubiquitously expressed in lymphocytes and macrophages. $\mathrm{ERR} \alpha$ is best described in classical metabolic tissues, including muscle and adipose, where it can promote expression of target genes involved in mitochondrial biogenesis, fatty acid metabolism, and oxidative phosphorylation. Functionally, ERR $\alpha^{-/-}$animals have systemic nutritional defects and do not respond well to metabolic stress conditions (39, 42, 43). $\mathrm{ERR} \alpha$ expression is also associated with a number of cancers and correlates with poor prognosis (44-47), and Drosophila ERR has been shown to be important for larval carbohydrate metabolism to support rapid cell growth and proliferation (48). ERR $\gamma$ can have the opposite function to that of ERR $\alpha$ and can be expressed in $\mathrm{T}$ cells $(40,49)$. These data suggest a broad role for ERR family members in metabolism and metabolic transitions $(39,40)$.

Recent data also point to a potentially key role for $\mathrm{ERR} \alpha$ and $\mathrm{ERR} \gamma$ in immune function. It was shown in macrophages that IFN- $\gamma$ signaling can induce PGC1 $\beta$-dependent upregulation of $\mathrm{ERR} \alpha$ to promote the generation of mitochondrial-derived reactive oxygen species. This pathway was important in macrophage immunologic function, and $\mathrm{ERR} \alpha^{-/-}$macrophages failed to efficiently clear the intracellular pathogen Listeria monocytogenes (42). In addition, we recently demonstrated that $\mathrm{ERR} \alpha$ regulates metabolic pathways critical for $T$ cell activation and differentiation (50). ERR $\alpha$ deficiency or inhibition in $\mathrm{T}$ cells decreased the induction of a variety of $\mathrm{T}$ cell metabolic genes upon activation. Primarily mitochondrial genes that allow efficient usage of glucose through aerobic glycolysis were affected by $\mathrm{ERR} \alpha$ inhibition, but Glut1 and glucose uptake were also affected. Although it is not entirely clear which effects were directly due to inhibition of $\mathrm{ERR} \alpha$, this phenotype may be reminiscent of ERR-mutant Drosopbila in that ERR $\alpha$-deficient T cells appear to be poor at using glucose as a fuel for cell growth. Immunologically, ERR $\alpha$ deficiency or inhibition reduced inflammatory cytokine production and decreased generation of Teffs in an EAE model. In contrast, ERR $\gamma$ deficiency is seen in the systemic lupus erythematosus (SLE) susceptibility allele Sle1c2 and leads to decreased mitochondrial function and increased glucose metabolism (49). This phenotype is reminiscent of findings in $T$ cell-specific Glut1-transgenic animals that have elevated glucose metabolism and that develop a systemic inflammatory disorder $(23,27)$. Thus, ERR $\alpha$ and $\gamma$ appear to be selective transcriptional regulators of Teff metabolism that may provide metabolic targets to modulate immunity.

Regulation of lipid metabolism is also critical in T cell growth and activation, as cells must shift from lipid oxidation for ATP to lipid synthesis to make membranes for cell growth. This process is controlled in part through liver $\mathrm{X}$ receptors (LXRs). $\mathrm{LXR} \alpha$ and $\mathrm{LXR} \beta$ are
Estrogen-related receptor $\alpha(E R R \alpha$ also NR3B1): orphan nuclear receptor expressed on lymphocytes, which participates in regulation of both glycolytic and mitochondrial metabolism via interactions with coactivators and repressors

Estrogen-related receptor $\gamma(\mathrm{ERR} \gamma$; also NR3B3): related to ERR $\alpha$ and mutated in Sle1c2; promotes mitochondrial gene expression

Oxidative phosphorylation: energy-efficient metabolic program in which glucose-derived pyruvate is converted to acetyl-coA and funneled to the mitochondria for oxidation in the TCA cycle, producing up to 36 molecules of ATP for every 1 molecule of glucose; requires oxygen

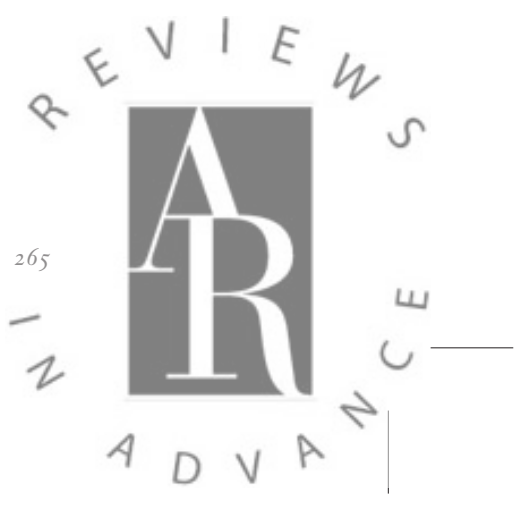


members of the nuclear receptor family and regulate cholesterol and lipid homeostasis. In particular, LXRs function to promote cholesterol efflux that balances lipid synthesis pathways stimulated through SREBP (sterol regulatory element-binding protein) transcription factors. In T cells, antigenic stimulation is followed by decreased LXR activity and increased activity of the SREBP-2 pathway for lipid and cholesterol synthesis (51). These changes in lipid and cholesterol homeostasis are critical for Teff activation and function, as pharmacologic activation of LXR can reduce $T$ cell proliferation and inflammatory function in response to immunization or in $\mathrm{EAE}$ (51-53). LXR $\beta^{-1-}$ animals developed splenomegaly, and $\mathrm{T}$ cells, upon stimulation, showed increased proliferation and cytokine production (51). Importantly, when ATP-binding casette transporter G1 (ABCG1)-dependent sterol transport was inhibited, LXR $\beta$ signaling was uncoupled from $T$ cell proliferation, and LXR $\beta$ agonism was unable to suppress proliferation. These data suggest that LXR $\beta$ and regulation of cholesterol and lipid efflux versus synthesis act as key regulators of $\mathrm{T}$ cell proliferation.

\section{POSTTRANSCRIPTIONAL REGULATORS OF T CELL METABOLISM}

\section{The PI3K/Akt/mTOR Pathway Coordinates Cell Growth}

Increased glycolysis and metabolic reprogramming upon $\mathrm{T}$ cell activation are costimulation dependent (54). In particular, CD28 signaling to activate the $\mathrm{PI} 3 \mathrm{~K} / \mathrm{Akt} / \mathrm{m}$ TOR pathway is critical. This pathway plays a number of key roles to promote the glucose metabolism and aerobic glycolysis essential for cell growth and proliferation. Activation of PI3K as a consequence of CD28 ligation leads to generation of phosphatidylinositol 3-phosphate, which recruits Akt isoforms 1-3 and 3-phosphoinositide-dependent protein kinase-1 (PDK1) to the cell membrane. PDK1 then phosphorylates Akt, which, together with phosphorylation by the mTOR complex 2 (mTORC2), activates Akt. In turn, Akt initiates a signaling cascade that results in the activation of mTORC1. Both Akt and mTORC1 can then promote aerobic glycolysis to support Teff growth and function.

Although Akt and mTORC1 can influence gene transcription through a number of mechanisms, these kinases also promote glucose metabolism via posttranslational effects. Akt plays a key role in the regulation of glucose transporters and glycolysis. A family of 14 facilitative glucose transporters mediates glucose uptake. Akt is well characterized in classical metabolic tissues to promote Glut4 translocation to the cell surface in response to insulin signaling. T cells do not typically express Glut 4 and instead predominantly express Glut1. We and others have shown that Akt also promotes trafficking of the glucose transporter Glut1 to the cell surface and prevents Glut1 internalization upon activation $(10,55)$. Akt can similarly promote cell surface trafficking of amino acid transport proteins $(56,57)$. The mechanism by which Akt controls Glut1 trafficking in lymphocytes is not certain; however, in other systems, TBC1D1 and TBC1D4 act as Akt substrates that can modify Glut1 trafficking to the cell surface (58). Both TBC1D1 and TBC1D4 are GTPase-activating proteins in the Rab family, and Rab proteins play important roles in the trafficking of proteins, including Glut1. For example, Rab11 can promote increased endosomal recycling of Glut1 to the cell surface (59), whereas Rab7 promotes Glut1 trafficking to lysosomes $(60,61)$. In addition to stimulating Glut1 cell surface trafficking, Akt can directly phosphorylate glycolytic enzymes to promote increased glycolytic flux. For example, hexokinase II (HKII) can be phosphorylated by Akt to promote HKII localization to the mitochondria and increased enzymatic activity $(62,63)$.

Downstream of Akt, activation of mTORC1 also promotes posttranslational events to stimulate aerobic glycolysis and coordinate pathways to support cell growth (64). One of the major functions of the mTORC1 complex is to phosphorylate 4EBP and p70S6 kinase (p70S6K) to 
promote increased protein translation. Activation of p70S6K may mediate many of the direct glycolytic effects of mTORC1, as p70S6K deficiency prevents increased glycolysis in PTENdeficient cells (65). SREBP2 is also activated by mTORC1 to promote lipid synthesis (66). This increase in lipid synthesis is coordinated with an Akt/mTORC1-dependent decrease in expression of CPT1a. As a rate-limiting factor in lipid uptake into mitochondria for oxidation, reduced CPT1a lowers lipid oxidation and conserves lipids for growth rather than for ATP generation (67). The mTORC1 complex has been particularly important in regulation of $\mathrm{T}$ cells as the target of the immunosuppressant rapamycin. Indeed, rapamycin treatment prevents increased glycolysis upon $\mathrm{T}$ cell activation and blocks $T$ cell growth and proliferation, leading instead to a state of anergy (68).

\section{AMP-Activated Protein Kinase}

Working in opposition to mTORC1 is the AMP-activated protein kinase (AMPK) complex. Whereas mTORC1 promotes anabolic processes to stimulate cell growth, AMPK is a well-known energy regulator that maximizes energy generation by promoting catabolic pathways (69). The AMPK complex is activated by an increased ratio of AMP to ATP and requires phosphorylation. Several kinases can activate AMPK, including liver kinase B1 (LKB1) and calcium/calmodulin-dependent protein kinase kinase II (CaMKKII) (70). LKB1 was first identified as the tumor suppressor responsible for Peutz-Jeghers syndrome, an autosomal dominant disorder that leads to intestinal hamartomas, mucocutaneous lesions, and an increased risk of spontaneous epithelial carcinomas $(71,72)$. LKB1 is essential for AMPK activation under conditions of bioenergetic stress (73-75), and $\mathrm{T}$ cell-specific knockout of LKB1 resulted in a partial blockade in thymocyte development at the DN3-4 transition and an overall reduction in peripheral $\mathrm{T}$ cells (76-78). T cells lacking LKB1 displayed defects in cellular proliferation and survival upon activation and in response to metabolic stress (78).
LKB1-deficient $T$ cells also displayed alterations in both glycolytic and lipid metabolism, with increased rates of glycolysis and decreased ability to upregulate lipid oxidation under stress (78). Despite poor proliferation, LKB1deficient $\mathrm{T}$ cells showed increased levels of $\mathrm{T}$ cell activation marker expression and inflammatory cytokine production at baseline and increased inflammatory cytokine production upon TCR stimulation (78). AMPK $\alpha 1^{-/-} \mathrm{T}$ cells also showed decreased ability to respond to metabolic stress and to transition from glycolytic and anabolic metabolism to lipid oxidation and catabolic metabolism but lacked the activation or cell survival defects of LKB1 deficiency (78), suggesting that other LKB1 substrates may regulate $\mathrm{T}$ cell survival and proliferation. AMPK is transiently activated not only under conditions of metabolic stress but also upon $\mathrm{T}$ cell activation, although calcium-mediated activation of CaMKKII may mediate this effect (70). The precise role and regulation of AMPK in early activation of $\mathrm{T}$ cells is unknown, but the complex may allow $T$ cells to rapidly stimulate energy-generating processes to prepare cells for rapid cell growth.

When activated, AMPK promotes energy generation and inhibits mTORC1 activation. AMPK has a wide variety of metabolic substrates, including acetyl-CoA carboxylase. Acetyl-CoA carboxylase phosphorylation by AMPK inhibits malonyl-CoA synthesis (69), and, as malonyl-CoA is a precursor in lipid synthesis and an inhibitor of CPT1a, this suppresses lipid synthesis and instead promotes lipid oxidation. AMPK can also phosphorylate tuberous sclerosis complex 2 at a site that prevents mTORC1 activation (68). This regulation of mTORC1 by AMPK may be critical to balance these opposing pathways, as $\mathrm{AMPK} \alpha 1^{-/-} \mathrm{T}$ cells had high basal levels of mTORC1 activation and glycolysis (78). ULK1 and ULK2 are also AMPK substrates and can promote autophagy (79). Autophagy leads to the engulfment and lysosomal degradation of cytoplasmic material and plays roles both in cellular quality control and as an intracellular source of nutrients if
AMP-activated protein kinase (AMPK): metabolic regulator that senses energy deficiency whose activation promotes ATP-producing metabolic pathways while downregulating ATP-consuming pathways

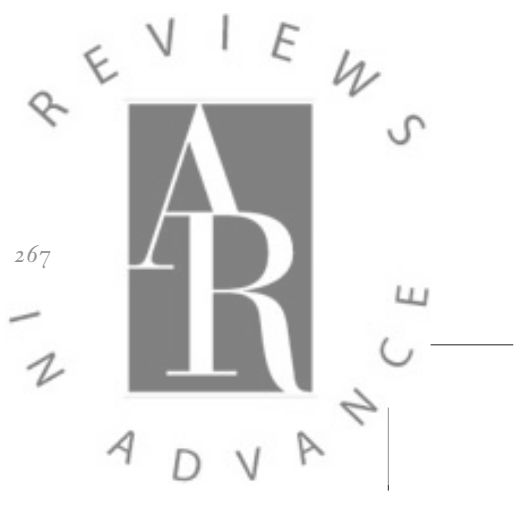




\section{MACROAUTOPHAGY}

Macroautophagy is a metabolic stress response pathway activated by AMPK and suppressed by mTORC1 that leads to engulfment and lysosomal degradation of intracellular cytoplasmic organelles or material. This process is highly conserved and can provide a nutrient source when extracellular nutrient uptake is insufficient to meet cell demands. In particular, degradation of long-lived proteins or cytoplasmic membranes can supply amino acids or lipids to mitochondria for oxidative metabolism when the rate of glycolysis is low (154). Autophagy is induced early in T cell activation and is essential for T cell proliferation and survival (80, 155). Both inhibition of autophagy and conditional knockout of Atg7 (a key autophagy-related protein) in T cells suppress activation (81). Autophagy may provide an essential metabolic fuel source and/or serve as a mechanism for cellular remodeling as a way to remove potentially damaged mitochondria and regulate mitochondrial turnover during $\mathrm{T}$ cell development (156). Autophagy has also been shown to contribute to antigen presentation on MHC class II molecules expressed on dendritic cells and is critical for thymic epithelial cells, in which it plays a key role in thymocyte selection (157). Altogether, autophagy has a central role in regulating energy metabolism in lymphocytes.

extracellular nutrient uptake is insufficient (see Macroautophagy sidebar). $\mathrm{T}$ cell stimulation leads to a transient activation of autophagy that is essential for $\mathrm{T}$ cell survival and activation (80, 81), and AMPK may contribute to this response.

\section{METABOLIC EFFECTS ON T CELL ACTIVATION AND MEMORY}

$\mathrm{T}$ cell metabolism is intimately linked to $\mathrm{T}$ cell function and differentiation. Upon recognition of cognate antigen in the presence of self-MHC and costimulatory signals, T cells grow, proliferate, and ultimately differentiate into distinct subsets that possess unique roles in maintaining functional responses and regulating immune homeostasis (82). Activated CD4 ${ }^{+}$
T cells can respond to specific cytokine signals to differentiate into distinct helper $\mathrm{T}$ cell $(\mathrm{Th})$ subsets that contribute to cellular, humoral, and mucosal immunity or that suppress $\mathrm{T}$ cell activation and excessive inflammatory responses (21). Activated $\mathrm{CD}^{+}{ }^{+} \mathrm{T}$ cells differentiate to provide an antigen-specific cytolytic defense against intracellular pathogens and tumors. Importantly, both $\mathrm{CD}^{+}$and $\mathrm{CD} 8^{+}$ $\mathrm{T}$ cells are capable of becoming long-lived memory cells that provide protection against secondary infection. Recently, it has become increasingly apparent that $\mathrm{T}$ cell activation does not lead to a uniform metabolic reprogramming in all conditions. In addition to their distinct functions, specific $\mathrm{T}$ cell lineages also possess unique metabolic profiles that are essential for their function and maintenance and may offer a new direction for modulation of the immune response (Figure 2).

\section{$\mathrm{CD}^{+}{ }^{+} \mathrm{T}$ Cell Differentiation}

$\mathrm{CD}^{+}$effector Th1, Th2, and Th17 cells (Teffs) and $\mathrm{CD}^{+}$regulatory $\mathrm{T}$ cells (Tregs) are the best-defined $\mathrm{CD}^{+}{ }^{+} \mathrm{T}$ cell subsets at the metabolic level. The first evidence suggesting that these subsets may be metabolically distinct came from studies dissecting the contribution of mTOR to T cell differentiation. The studies showed that treatment of $\mathrm{T}$ cells with rapamycin to suppress mTORC1 prevents Teff cell growth and proliferation, leading to anergy, and promotes Treg generation (83, 84). In support of these pharmacologic studies, T cell-specific mTOR deficiency showed that mTOR is required selectively in Teffs and that $\mathrm{mTOR}^{-1-}$ T cells can only generate Tregs upon activation (85). Indeed, Tregs have low mTORC1 function basally and instead have increased levels of AMPK activation. Further, stimulation of AMPK in vivo with the AMPK activator metformin can increase Treg numbers (27). Changes in mTOR signaling and in mTORC1 and mTORC2 also show selectivity among the Teff subsets (86). Genetic deletion of Rheb selectively prevents mTORC1 activation and suppresses Th1 and Th17 generation 


\section{Cell type: \\ Predominant metabolic program: \\ Key regulator:}

Function:
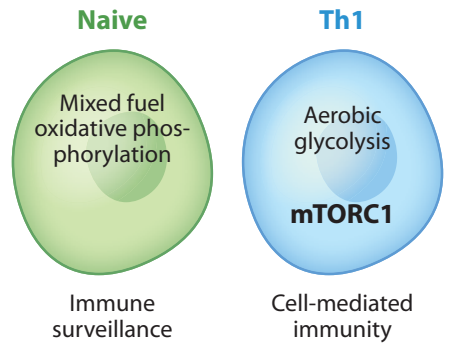
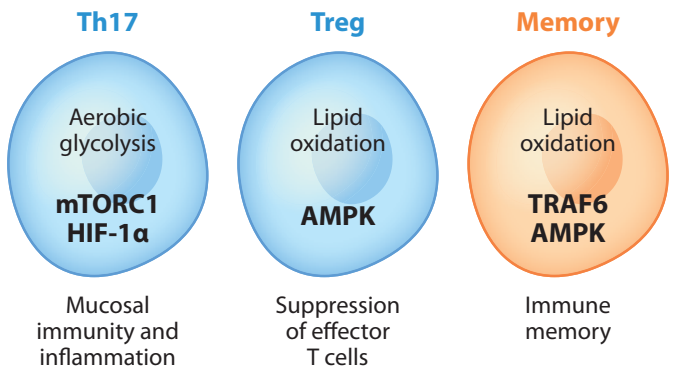

Figure 2

Specific $\mathrm{T}$ cell lineages possess unique metabolic profiles that are essential for their function and maintenance. The predominant metabolic program and key regulators are highlighted for each of the T cell subtypes shown here.

but allows Th2 cells to generate normally or potentially to a higher degree. In contrast, deficiency in T cell-specific Rictor, a component of mTORC2, prevents only Th2 cell generation, leaving Th1 and Th17 intact. Altogether, all Teffs require mTOR, but whereas Th1 and Th17 cells require mTORC 1 activity, Th2 cells require mTORC2.

Consistent with the opposing metabolic programs coordinated by mTOR and AMPK, it is now clear that $\mathrm{CD}^{+}{ }^{+} \mathrm{T}$ cell subsets are metabolically distinct. In particular, Teffs and Tregs show sharp differences. Activation of mTOR plays a key role in glycolysis and Teff fate. We found that in vitro differentiated Th1, Th2, and Th17 cells cultured in IL-2 each had higher total cellular and cell surface Glut 1 compared with Tregs (27). Although all cells had higher rates of glycolysis than naive $\mathrm{T}$ cells, Tregs were also the least glycolytic of the subsets. Importantly, Tregs were not generally metabolically inactive and instead had elevated rates of lipid oxidation and mitochondrial membrane potential that were consistent with the observed high level of phosphorylated AMPK. Similar results, showing preferential glycolysis in Teffs and lipid oxidation of Tregs, were described by Shi et al. (30).

The metabolic differences between $\mathrm{CD}^{+}$ $\mathrm{T}$ cell subsets likely support important cellspecific functional requirements, but they are also key drivers and essential for the generation and survival of these subsets. The increased Glut1 expression of Teffs prompted examina- tion of $\mathrm{T}$ cell subsets in transgenic animals with T cell-specific expression of Glut1. Glut1transgenic $\mathrm{T}$ cells were readily activated and showed increased proliferation and cytokine secretion (23). As transgenic animals aged, however, a lymphadenopathy and inflammatory disease became evident. Importantly, only Teffs accumulated, and peripheral lymphoid $\mathrm{T}$ cells were readily able to produce IL-2, IL-4, and IL-17 in aged Glut1-transgenic animals; Tregs, in contrast, remained at normal frequency (27). Increased glucose uptake, therefore, is sufficient in vivo to selectively enhance Teff function. Conversely, inhibition of glucose metabolism either by withdrawal of glucose in cell cultures or by the addition of the hexokinase inhibitor 2DG was capable of selectively inhibiting Teffs in vitro $(27,30)$. This was true in vivo as well, as treatment with 2DG protected animals from EAE (30). Modulation of lipid metabolism can also impact Teff and Treg fate, as provision of lipids suppressed Teff generation but enhanced Treg generation, and inhibition of CPT1a and mitochondrial lipid oxidation selectively inhibited Treg differentiation (27).

The balance of cell metabolism by mTOR/AMPK signaling also has important implications for metabolic regulation of neighboring cells. Cobbold et al. (87) showed that the interaction between antigen-presenting cells and Tregs results in the induction of essential amino acids (EAA)-consuming pathways that lead to the depletion of EAA in neighboring naive $T$ cells (87). The loss of microenviron-

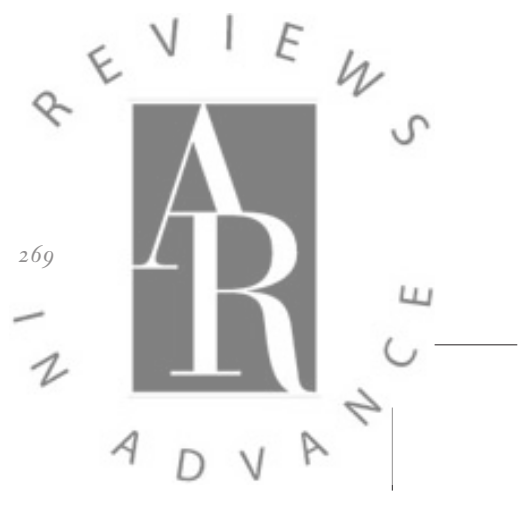


Hypoxia inducible factor-1 $\alpha(\mathrm{HIF}-1 \alpha)$ : transcription factor that is stabilized in response to hypoxia and activated following mTORC1 activation; promotes cellular glycolysis and Th17 differentiation

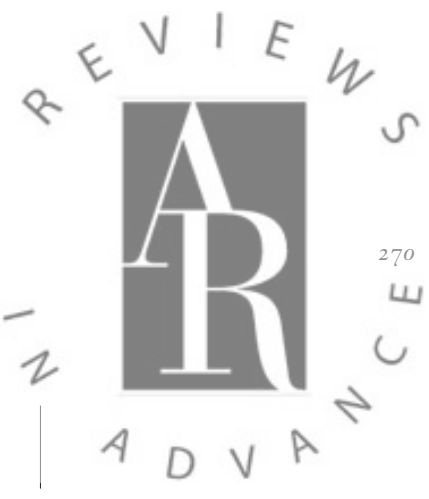

mental EAA disrupts mTORC1 signaling and subsequently primes naive $\mathrm{T}$ cells to become Foxp $3^{+}$Tregs. The restriction of EAA may also result in anergy in existing Teff populations similar to the aberrant $\mathrm{T}$ cell function that occurs in the presence of the leucine metabolism inhibitor N-acetyl-leucine amide (NALA) (29). Tregs may also exploit metabolic pathways to suppress Teffs by altering glutathione metabolism and inducing oxidative stress (88).

Similar to the selective regulation of Teff and Treg metabolism by mTOR and AMPK, the hypoxia inducible factor- $1 \alpha(\mathrm{HIF}-1 \alpha)$ is an important transcription factor for selectively regulating the metabolism of Th17 cells. $\mathrm{HIF}-1 \alpha$ is best appreciated for its role in the hypoxic response, in which hypoxia reduces HIF-1 $\alpha$ prolyl-hydroxylation to prevent HIF$1 \alpha$ ubiquitination by the VHL E3 ubiquitin ligase complex (89). Given hypoxic areas in lymphoid, the gut, and inflamed tissues, this pathway may play an important role in $\mathrm{T}$ cell metabolism. HIF-1 $\alpha$ can also, however, be regulated by nonoxygen-dependent pathways, such as increased mTORC1-dependent protein translation upon activation of the $\mathrm{PI} 3 \mathrm{~K} / \mathrm{Akt} / \mathrm{m}$ TOR pathway. When accumulated, HIF- $1 \alpha$ associates with HIF-1 $\beta$ (ARNT) to promote the expression of all glycolytic genes, including the gene encoding Glut1. Although unnecessary to allow $\mathrm{T}$ cells to upregulate glycolytic gene expression in the initial day of $\mathrm{T}$ cell activation (36), HIF-1 $\alpha$ is selectively expressed in differentiated Th17 cells (30). HIF-1 $\alpha$ plays a key role in $\mathrm{T}$ cell fate at this stage, as HIF-1 $\alpha$ deficiency suppressed Th17 and instead increased Treg development (30, 90). The mechanism by which HIF-1 $\alpha$ regulates Th17 and Treg development is not certain but appears to involve both metabolic and nonmetabolic pathways. Metabolically, the induction of glycolysis by HIF- $1 \alpha$ likely favors Th17 over Tregs. Nonmetabolically, HIF-1 $\alpha$ directly increases the transcriptional activity of the Th17-determining transcription factor ROR $\gamma t$ at the IL-17 locus. HIF-1 $\alpha$ can also bind the Treg-determining transcription factor Foxp3, leading to Foxp3 degradation (90). The metabolic and signaling interactions of hypoxia and HIF- $1 \alpha$ may have broad impact on T cells and will be important for future studies.

\section{$\mathrm{CD8}^{+} \mathrm{T}$ Cell Differentiation and Memory}

Like effector $\mathrm{CD}^{+}{ }^{+} \mathrm{T}$ cells, resting $\mathrm{CD}^{+} \mathrm{T}$ cells undergo dynamic shifts in cell metabolism and switch from an oxidative metabolism to aerobic glycolysis upon activation (91). This transition is essential to support growth and differentiation into cytotoxic $\mathrm{T}$ cells capable of dividing every six to eight hours and of producing inflammatory cytokines and the cytolytic granules perforin and granzyme-B. Following pathogen clearance, however, the majority of $\mathrm{CD}^{+}$cytotoxic $\mathrm{T}$ cells succumb to apoptosis, although a small percentage further differentiate into long-lived quiescent memory $\mathrm{CD}^{+}{ }^{+} \mathrm{T}$ cells. In this phase, $\mathrm{CD} 8^{+} \mathrm{T}$ cells no longer undergo rapid growth requiring high rates of biosynthesis and instead once again require efficient energy generation to support basic cellular functions and prevent cell death.

The mTOR pathway plays a key role in these metabolic shifts. Although the mTORC1 inhibitor rapamycin can suppress $T$ cell activation when given early, lower or delayed rapamycin treatment did little to impact the primary $\mathrm{T}$ cell response but paradoxically increased $\mathrm{CD}^{+}$ T cell memory $(92,93)$. Mechanistically, rapamycin treatment reduced mTORC1 activity and led to increased AMPK phosphorylation that correlated with an increased ability of $\mathrm{CD}^{+} \mathrm{T}$ cells to perform lipid oxidation (93). Metabolically, $\mathrm{He}$ et al. (91) showed that rapamycin inhibition of mTORC1 did not significantly slow the glycolytic metabolism of activated $\mathrm{CD}^{+}{ }^{+} \mathrm{T}$ cells, but it did increase lipid oxidation in such a way as to protect cells from apoptosis upon either cytokine or glucose deprivation. Moreover, the signaling protein TRAF6 plays a key role for $\mathrm{CD}^{+}{ }^{+} \mathrm{T}$ cells to switch from glycolytic to oxidative metabolism, and $\mathrm{TRAF}^{-/--} \mathrm{CD}^{+} \mathrm{T}$ cells had impaired memory responses due to an apparent inability to activate AMPK and induce lipid oxidation 
(93). The mechanisms by which TRAF6 regulates metabolism remain unclear, but TRAF6 is a well-described regulator of nuclear factor- $\mathrm{kB}$ $(\mathrm{NF}-\mathrm{KB})$, which may influence this process (94).

Similar to resting $\mathrm{T}$ cells and $\mathrm{CD}^{+}{ }^{+}$Tregs, memory $\mathrm{CD}^{+} \mathrm{T}$ cells not only favor but depend on lipid oxidation. Memory T cells express high levels of the mitochondrial lipid transporter CPT1a, and inhibition or RNAi of this protein diminished mitochondrial function and reduced memory cell survival. Conversely, retroviral CPT1a expression enhanced $\mathrm{CD}^{+}$ memory cell generation in an adoptive transfer model (95). Many of these metabolic changes were regulated through the induction of mitochondrial biogenesis and increased capacity of cells to undergo oxidative metabolism under metabolic stress, a characteristic quantified as spare respiratory capacity (95). Spare respiratory capacity refers to the excess capacity of mitochondria to further induce respiratory metabolism upon metabolic stress. The precise role for spare respiratory capacity and at what point $\mathrm{CD}^{+}{ }^{+} \mathrm{T}$ cells undergo metabolic stress in vivo is not fully understood, but the above findings imply that the metabolic reprogramming of $\mathrm{CD}^{+}{ }^{+} \mathrm{T}$ cells from a glycolytic state back to an oxidative state is itself a key element to allow selection and survival of memory cells.

\section{T CELL DYSFUNCTION AND METABOLISM IN ANERGY AND EXHAUSTION}

Acute T cell stimulation with foreign pathogens leads to a rapid and productive immune response, as described above. Chronic stimulation with self-antigen or upon chronic infection, however, results in self-tolerance or exhaustion that prevents or reduces $\mathrm{T}$ cell proliferation and effector function. In this respect, tolerant or exhausted $T$ cells resemble naive or memory $T$ cells, requiring energy-generating metabolic processes rather than biosynthesis. Evidence increasingly shows that regulation of the balance of oxidative to glycolytic cell metabolism is a component of T cell anergy and exhaustion.

\section{T Cell Anergy}

$\mathrm{T}$ cell anergy is a state of hyporesponsiveness that acts to silence self-reactive T cells. Anergic cells fail to proliferate or produce appropriate levels of growth-promoting cytokines, such as IL-2, upon stimulation and often result from an absence of CD28-mediated costimulation during TCR engagement $(96,97)$. One of the main functions of costimulation by CD28 is to activate the $\mathrm{PI} 3 \mathrm{~K} / \mathrm{Akt} / \mathrm{m}$ TOR pathway, which allows full $\mathrm{T}$ cell activation rather than induction of anergy. The role of mTORC1 activation in $\mathrm{T}$ cell stimulation and anergy is highlighted by the finding that rapamycin is sufficient to induce $\mathrm{T}$ cell anergy even in the presence of costimulation (98). As discussed above, activation of the PI3K/Akt/mTOR pathway stimulates Akt- and mTOR-dependent trafficking of Glut1 and amino acid transporters to the cell surface and upregulates glycolysis and other anabolic processes $(59,83,99)$. Thus, costimulation is a critical step to facilitate the increased nutrient uptake necessary to fuel aerobic glycolysis and multiple anabolic pathways. Failure to receive costimulation therefore prevents stimulated $\mathrm{T}$ cells from upregulating glucose uptake and inducing aerobic glycolysis (29). In addition to reduced glucose metabolism, anergic $\mathrm{T}$ cells also fail to upregulate the amino acid transporter CD98 and the transferrin receptor CD71 (29), which may be important for growth and mitochondrial metabolism. Importantly, the addition of IL-2 is able to stimulate the $\mathrm{PI} 3 \mathrm{~K} / \mathrm{Akt} / \mathrm{mTOR}$ pathway in anergic $\mathrm{T}$ cells to restore $\mathrm{T}$ cell metabolism, growth, and function (100).

$\mathrm{T}$ cell anergy may be partially due to an inability of the cell to broadly coordinate metabolic pathways for growth and function. Consistent with this notion, it is now clear that the metabolic pathways themselves can be key regulators of $\mathrm{T}$ cell anergy. Directly limiting $\mathrm{T}$ cell metabolism during activation with the addition of the glucose analog 2DG or the leucine analog NALA led to T cell anergy (29). This anergic state was rescued by the addition of IL-2 to activate the PI3K/Akt/mTOR
Exhaustion: result of chronic $\mathrm{T}$ cell stimulation leading to nonresponsiveness

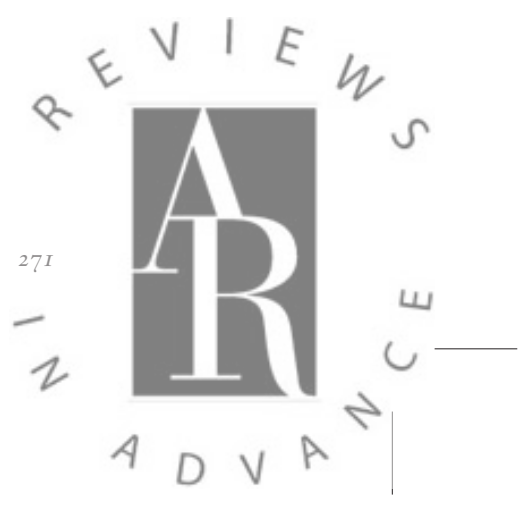


pathway, provided that 2DG and NALA were not present. Presence of metabolic inhibitors, however, overcame costimulatory signals, indicating that cell metabolism is necessary downstream of costimulatory signals. Thus, T cell activation requires a metabolic checkpoint, and if glucose metabolism is insufficient, $\mathrm{T}$ cells appear unable to fully activate mTORC1 and become anergic rather than activated.

\section{T Cell Exhaustion}

Just as an absence of efficient costimulatory signals can result in T cell anergy (97), chronic $T$ cell stimulation can induce a state of $T$ cell nonresponsiveness termed exhaustion as a result of constant antigen exposure during diseases such as chronic viral infection and cancer (101, 102). Exhausted T cells are unable to provide protection against secondary infection, are defective in their capacity to self-renew through homeostatic proliferation, and have diminished cytokine production and cytolytic capacity. Reactivating exhausted $\mathrm{T}$ cells holds potential as treatment for a variety of chronic viral infections. Although the molecular mechanisms of T cell exhaustion are not fully understood, recent studies have started to highlight a potentially important role for cellular metabolism.

In the process of identifying a molecular signature for $\mathrm{CD}^{+} \mathrm{T}$ cell exhaustion in chronic viral infection, Wherry et al. (103) reported that various genes involved in cell metabolism were altered in exhausted $\mathrm{CD} 8^{+} \mathrm{T}$ cells. Expression of glycolytic genes was reduced, and exhausted $T$ cells instead appeared to favor expression of genes involved in oxidative metabolism. Although correlative, these findings suggest that a deficit in glucose metabolism contributes to $T$ cell exhaustion in much the same way that it contributes to T cell anergy. Further supporting a potential connection of cell metabolism to exhaustion, some of the extracellular inhibitory receptors associated with exhaustion are CD28 family members that have been linked to changes in intracellular metabolic signaling pathways. Multiple studies have implicated the inhibitory CD28 family members cy- totoxic T-lymphocyte antigen-4 (CTLA-4) and programmed death-1 (PD-1) in the suppression of chronically stimulated $\mathrm{T}$ cell proliferation and function (104-106). In the case of CTLA-4, ligation of this receptor has been shown to terminate PI3K/Akt signaling (107), thereby diminishing glucose metabolism that is required for optimal cell growth and function $(23,54)$. Similarly, ligation of PD-1 can inhibit both mTORC1 and mTORC2 signaling, thus diminishing glycolytic metabolism within the target cell (108). Aside from inhibitory receptors, downregulation of the costimulatory receptor CD28 itself is also observed following repetitive stimulation and in aged individuals (109), and this may contribute to reduced $\mathrm{T}$ cell activity in these cases.

Metabolic changes in T cell exhaustion may also be mediated by extracellular sources. Lymphocyte metabolism is regulated by cytokines that can be disrupted or persist in chronic infection. Cytokines can be potent regulators of Glut1 trafficking and glycolysis, and IL-2 can promote Glut1 expression and glucose uptake in activated T cells (110). In exhaustion, however, $\mathrm{T}$ cells have reduced production of IL2 , and this may contribute to reduced glucose metabolism of exhausted T cells (103). Navarro et al. (111) demonstrated that, unlike IL-2, the antiviral cytokine type I IFN member IFN- $\alpha$ diminished glucose and glutamine metabolism in activated lymphocytes. This defect was characterized by decreased activity of the metabolic enzymes glucose-6-phosphate dehydrogenase (G6PDH), citrate synthase, and phosphate-dependent glutaminase. The alteration in G6PDH activity limits the generation of glucose-derived nucleotides through the pentose phosphate pathway, thereby limiting the proliferation of the cells. Together, these studies demonstrate that soluble and receptor interactions induce changes in metabolic pathways and machinery in cells that ultimately diminish their ability to utilize aerobic glycolysis for growth. A remaining key concern is to directly establish to what extent failure to induce glucose metabolism and aerobic glycolysis contributes to $\mathrm{T}$ cell exhaustion. 


\section{CLINICAL CORRELATIONS}

\section{T Cell Metabolism in Autoimmune and Allergic Disease}

Unregulated and dysfunctional lymphocyte responses are a hallmark of autoimmune and allergic diseases, such as asthma, arthritis, and SLE. Similar to exhausted T cells, lymphocytes from patients with these diseases are often repetitively stimulated due to repeated or constant antigen exposure. Because of the unbalanced regulation of these immune responses, $\mathrm{T}$ cells from allergic and autoimmune models exhibit an altered metabolic profile compared with healthy lymphocytes. Ostroukhova et al. (112) observed increased levels of the glycolytic by-product lactate in the blood of patients that directly correlated with the severity of each patient's asthma. Isolation of $\mathrm{CD}^{+}{ }^{+} \mathrm{T}$ cells from either asthmatic patients or a murine model of asthma revealed that these cells exhibited elevated lactate production upon stimulation compared with controls, suggesting that a glycolytic lymphocyte response may contribute to the disease. These effects were partially due to increased expression of the pyruvate dehydrogenase inhibitor pyruvate dehydrogenase kinase 1 (PDHK1), resulting in the inhibition of the pyruvate dehydrogenase complex $(\mathrm{PDH})$ and the promotion of the conversion of pyruvate to lactate instead of to acetyl-CoA. Importantly, the PDHK1 inhibitor dichloroacetate (DCA) limited lactate production and alleviated inflammation and airway responsiveness in mice. Similar findings were reported in a murine model of collagen-induced arthritis, in which DCA treatment reduced glycolysis and disease (113). These results suggest that the inflammatory response may be limited by both the availability of a metabolic fuel and the cellular machinery that directs it to its final destination-that is, the conversion of pyruvate to acetyl-CoA for mitochondrial oxidation versus the shuttling of pyruvate to lactate to maintain aerobic glycolysis.

The difference between the utilization of metabolic fuel inside and outside the mitochondria is an important consideration when examining the metabolic phenotype of autoreactive lymphocytes from SLE patients. Lymphocytes isolated from SLE patients have increased mitochondrial oxidation and reactive oxygen species generation, which may be due to dysfunctional mitochondria (114-116). Similar observations were made in a murine lupus model in which glycolytic flux was indistinguishable from healthy cells, but mitochondrial glucose oxidation was significantly increased (117). In contrast to asthma, in which elevated PDHK1 levels suggest that glucose is produced by $\mathrm{T}$ cells predominantly outside of the mitochondria (112), the generation of ATP in chronically stimulated cells from autoimmune models is derived primarily from oxidative metabolism. This selective dependency on mitochondrial metabolism may contribute to findings that inhibition of the mitochondrial F1/F0 ATPase can promote apoptotic death of chronically stimulated $\mathrm{T}$ cells in models of SLE but not of resting or acutely activated $\mathrm{T}$ cells $(118,119)$. Increased reliance on mitochondrial metabolism is also similar to other autoimmune pathogenic conditions such as graft-versus-host disease (GVHD) and rheumatoid arthritis (117, 120-122).

Bone marrow transplant illustrates another example in which metabolism may impact immunologic disease. If bone marrow is not fully matched, resident $T$ cells can induce GVHD. In GVHD, alloreactive T cells from the donor recognize host $\mathrm{MHC}$ and cause direct damage to recipient tissues and organs as well as indirect complications (i.e., infections that result from the increased need for immunosuppressants required to keep GVHD in check). Whereas activated lymphocytes typically use a program of primarily aerobic glycolysis, the strong and chronic activation of alloreactive $\mathrm{T}$ cells in GVHD demonstrates increases in both aerobic glycolysis and oxidative phosphorylation (119). This is specific to the T cells and in contrast to the glycolytic phenotype of the proliferating transplanted hematopoietic stem cells. The alloreactive $T$ cells further exhibit mitochondrial hyperpolarization and increased oxidative stress that can be pharmacologically targeted to selec-

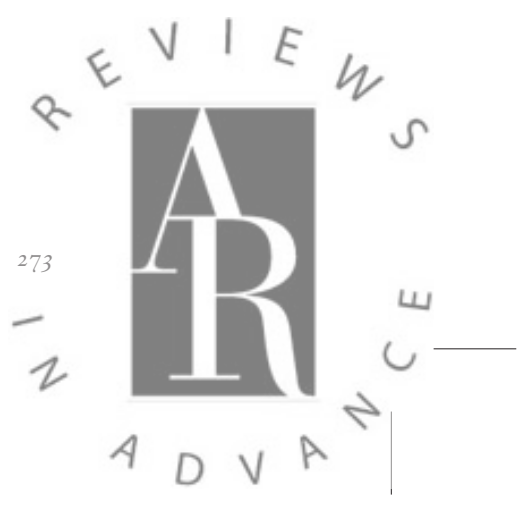


tively induce apoptosis in autoimmune cells and limit the severity of the disease (119).

The upregulation of oxidative phosphorylation in GVHD alloreactive $\mathrm{T}$ cells is surprising given the typical program of aerobic glycolysis in normally activated $\mathrm{T}$ cells and highlights the metabolic dysregulation that can occur in diseased states. Moreover, the contrast between glycolytic metabolism and mitochondrial metabolism in allergic and autoimmune diseases, respectively, demonstrates an important and critical difference for metabolic dependency between chronic versus repetitive stimulation that may provide opportunities for metabolic intervention of specific inflammatory responses.

\section{Nutrition and Immune Cell Metabolism}

The metabolic and nutritional status of the organism as a whole also has a critical role in regulating immunity. Obesity is a growing epidemic in developed countries and is associated with life-threatening comorbidities such as diabetes and cardiovascular disease, which increase medical costs and shorten life span. Exacerbating the problem is the lack of effective treatments for obesity. Energy intake in excess of energy requirements leads to a biological response or defense to the elevated level of body fat mass that then leads to a low-level inflammatory state. Weight loss in obese patients is associated with a decrease of inflammatory biomarkers such as C-reactive protein, TNF- $\alpha$, and IL- 6 and is accompanied by improvement of metabolic parameters, especially insulin sensitivity (123). This was first demonstrated with TNF- $\alpha$ levels, which were found overexpressed in the adipose tissue of obese mice (124). Loss of TNF$\alpha$ in murine models of obesity resulted in improved insulin sensitivity and glucose homeostasis $(125,126)$, whereas exogenous administration of TNF- $\alpha$ led to insulin resistance (127).

In addition to TNF- $\alpha$, other inflammatory mediators and cytokines are also overexpressed in adipose and other tissues in murine models of obesity and in obese humans, and it is now clear that obesity is characterized by a broad inflammatory response $(128,129)$. Many inflammatory mediators exhibit patterns of expression and may impact insulin action in a manner similar to that of TNF- $\alpha$ during obesity. Macrophages were initially implicated as the cells that produce the inflammatory cytokines in question, as macrophages and adipocytes colocalize in adipose tissue in obesity (130). Expansion of adipose tissue leads to the release of chemokines that induce increased recruitment of M1, or classically activated, macrophages, which are characterized by increased production of the proinflammatory cytokines that promote altered gene expression and insulin resistance in adipocytes (as opposed to M2 macrophages, which secrete more anti-inflammatory cytokines) (129). These changes result in altered adipocyte secretion of cytokines (adipokines), increased lipolysis, and an excess of circulating nonesterified fatty acids, which may eventually contribute to systemic insulin resistance (131). Subsequently, many mouse studies have knocked out the macrophage inflammatory response pathway and demonstrated that macrophages residing in adipose tissue can in fact contribute to obesityrelated insulin resistance (130). Moreover, Vats et al. (132) have shown that M2 macrophages preferentially rely on oxidative metabolism like Tregs, whereas M1 macrophages exhibit a highly glycolytic metabolic profile similar to Teffs. These metabolic phenotypes are determined at both the intracellular and extracellular levels, as metabolites present in the tissue environment have been shown to influence the development of these immune responses.

More recently, studies have highlighted the finding that adipose-specific lymphocytes are critical and necessary precursors to the adipose-resident macrophages required for the inflammation and insulin resistance seen in obesity. In 2009, a series of studies demonstrated the importance of adipose tissue-associated $\mathrm{T}$ cells in obesity-induced inflammation (133-135), implicating roles for adipocyte-specific $\mathrm{CD}^{+} \mathrm{T}$ cells, $\mathrm{CD} 8^{+}$ $\mathrm{T}$ cells, and Tregs in controlling both local 
macrophage recruitment and systemic insulin resistance. In addition, visceral adipose tissue (VAT)-specific Tregs were recently characterized to differ from Tregs found in more traditional lymphoid compartments (136). Establishment of these VAT-specific Tregs from naive $\mathrm{CD}^{+}{ }^{+} \mathrm{T}$ cells depends upon collaboration of both Foxp 3 and PPAR- $\gamma$ expression. Conditional knockout of PPAR- $\gamma$ in the Treg lineage resulted in decreased VAT-specific Treg numbers but no change in the number of Tregs found in lymphoid tissue (136). This was accompanied by an increase in some, but not all, adipose tissue-specific monocyte/macrophage subsets. Importantly, use of the PPAR $-\gamma$ agonist pioglitazone accentuated the accumulation of VAT-specific Tregs and insulin sensitivity in obese mice (136). This finding suggests a novel mechanism by which the drug pioglitazone promotes insulin sensitivity through regulation of $\mathrm{T}$ cells rather than primarily by modulation of PPAR- $\gamma$ in adipocytes.

Obese individuals exhibit many symptoms of chronic low-grade inflammation that is partially driven by the expansion of Th17 cells. Clinically, obese humans can exhibit elevated levels of IL-17 (137). Furthermore, obesity can exacerbate disease in IL-17-dependent autoimmune models of EAE and colitis. IL-17 can also inhibit adipogenesis, suggesting that it may be produced in obesity to try to limit fat development. Indeed, IL-17R $\alpha^{-/-}$mice are overweight and have more significant obesity following a high fat diet (138) but, interestingly, show enhanced glucose tolerance and insulin sensitivity. The predisposition of obese individuals for a wide range of inflammatory diseases suggests that altered $\mathrm{T}$ cell function has a broad impact on diseases that may not be directly linked to adipose tissue.

One key adipokine that may contribute to the inflammation seen in metabolic disease and obesity is leptin. Leptin is secreted by adipocytes in proportion to fat volume and is best known for its effects on regulating appetite and metabolism via signaling at the level of the hypothalamus (139). However, leptin deficiency also results in altered immune responses, affecting both innate and adaptive immunity $(140,141)$. Leptin is a member of the class I cytokine family and signals via the Jak/STAT and Akt pathways, among others, to mediate its effects on immune cell number and function, leading to a proinflammatory (Th1) phenotype (142-144). Leptin is particularly important for $\mathrm{T}$ cells, as leptin-deficient individuals have decreased $\mathrm{T}$ cell numbers, decreased CD4 ${ }^{+}$Th cells, increased proliferation of Tregs, and skewed cytokine production, resulting in increased susceptibility to intracellular infections (145-147). Administration of recombinant leptin protein to leptin-deficient mice or humans reverses both the metabolic defects and immune abnormalities observed (148). Moreover, leptin contributes to activation of mTOR in Tregs and has been found to correlate with Treg hyporesponsiveness and constrained Treg proliferation (149). One could postulate that excess leptin secretion from adipocytes in the obese individual may have paracrine effects on local $\mathrm{T}$ cells and macrophages, which may go on to promote the development of the systemic inflammation and insulin resistance seen in metabolic syndrome.

Conversely, malnutrition, which plagues a large proportion of individuals in the developing world, is an immunosuppressive event that reduces immune function and markedly increases the risks and mortality from severe infections (150-152). Malnutrition is associated with a deficit of circulating leptin, resulting from generalized wasting and depletion of stores of adipose tissue (139). In a recent study, peripheral blood $\mathrm{T}$ cells were isolated from malnourished children hospitalized for infections. Culture of these $\mathrm{T}$ cells with leptin resulted in increased $\mathrm{T}$ cell activation following stimulation with PMA-ionomycin, as demonstrated by upregulation of CD25 and CD69 surface expression as well as increased effector cytokine (IL-2 and IFN- $\gamma$ ) production (153). Thus, leptin itself or the regulatory pathways that control leptin expression or function may be important new targets to promote immunity. This system makes sense evolutionarily, as

\section{Leptin:}

adipocyte-derived hormone that is well known for its role in regulating body weight and metabolism; also critical for normal $\mathrm{T}$ cell number and function

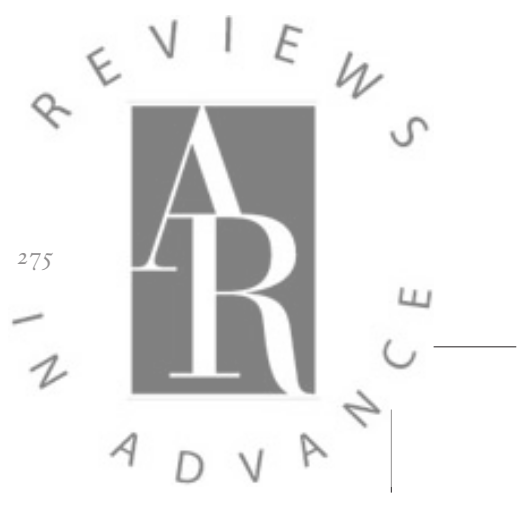


energy deficiency during times of food scarcity requires downregulation of nonessential and energy-consuming systems and pathways, such as immune cell activation. These concepts can be more broadly applied to augmenting immune response to vaccinations in malnourished children in underdeveloped areas of the world and to preventing infections in critically ill patients in intensive care unit settings.

\section{CONCLUSIONS}

Although the immune system has a critical role in protecting against infections and performing tumor surveillance, this task is highly energy demanding and must be finely regulated. We are beginning to understand how pathways that regulate immune cell number, function, and differentiation are linked to those regulating metabolism. These pathways are controlled by both transcriptional and posttranscriptional mechanisms that dictate both cell metabolism and function/differentiation. Manipulation of metabolic programs may offer therapeutic opportunities in altering immune response in conditions of either immunosuppression or inflammation. This has relevance to treatment of infections, vaccine response, tumor surveillance, autoimmunity, and inflammatory disorders. Moreover, the metabolic status of the organism as a whole can affect both lymphocyte function and lymphocyte metabolism on a cellular level. Metabolism, immunity, and nutrition are overlapping and intersecting systems with rich opportunities for development and understanding.

\section{DISCLOSURE STATEMENT}

The authors are not aware of any affiliations, memberships, funding, or financial holdings that might be perceived as affecting the objectivity of this review.

\section{ACKNOWLEDGMENTS}

This work was supported by NIH R01 HL108006 (J.C.R.) and K08 DK087944 (N.J.M.), the American Asthma Foundation (J.C.R. is the Bernard Osher Fellow of the AAF), the Lupus Research Institute (J.C.R), the Leukemia \& Lymphoma Society (J.C.R.), and an Irvington Institute Postdoctoral Fellowship from the Cancer Research Institute (R.D.M.).

\section{LITERATURE CITED}

1. Warburg O. 1956. On the origin of cancer cells. Science 123:309-14

2. Koppenol WH, Bounds PL, Dang CV. 2011. Otto Warburg's contributions to current concepts of cancer metabolism. Nat. Rev. Cancer 11:325-37

3. Warburg O, Gawehn K, Geissler AW. 1958. Metabolism of leukocytes. Z. Naturforsch. B 13B:515-16 (In German)

4. Swainson L, Kinet S, Manel N, Battini JL, Sitbon M, Taylor N. 2005. Glucose transporter 1 expression identifies a population of cycling $\mathrm{CD}^{+} \mathrm{CD}^{+}$human thymocytes with high CXCR4-induced chemotaxis. Proc. Natl. Acad. Sci. USA 102:12867-72

5. Yu Q, Erman B, Bhandoola A, Sharrow SO, Singer A. 2003. In vitro evidence that cytokine receptor signals are required for differentiation of double positive thymocytes into functionally mature $\mathrm{CD} 8^{+} \mathrm{T}$ cells. 7. Exp. Med. 197:475-87

6. Sandy AR, Jones M, Maillard I. 2012. Notch signaling and development of the hematopoietic system. Adv. Exp. Med. Biol. 727:71-88

7. Radtke F, Wilson A, Stark G, Bauer M, van Meerwijk J, et al. 1999. Deficient T cell fate specification in mice with an induced inactivation of Notch1. Immunity 10:547-58

MacIver • Michalek • Rathmell 
8. Pui JC, Allman D, Xu L, DeRocco S, Karnell FG, et al. 1999. Notch1 expression in early lymphopoiesis influences B versus T lineage determination. Immunity 11:299-308

9. Ciofani M, Zuniga-Pflucker JC. 2005. Notch promotes survival of pre-T cells at the $\beta$-selection checkpoint by regulating cellular metabolism. Nat. Immunol. 6:881-88

10. Gerriets VA, Rathmell JC. 2012. Metabolic pathways in T cell fate and function. Trends Immunol. 33:168-73

11. Wofford JA, Wieman HL, Jacobs SR, Zhao Y, Rathmell JC. 2008. IL-7 promotes Glut1 trafficking and glucose uptake via STAT5-mediated activation of Akt to support T-cell survival. Blood 111:2101-11

12. Pallard C, Stegmann AP, van Kleffens T, Smart F, Venkitaraman A, Spits H. 1999. Distinct roles of the phosphatidylinositol 3-kinase and STAT5 pathways in IL-7-mediated development of human thymocyte precursors. Immunity 10:525-35

13. Tan JT, Dudl E, LeRoy E, Murray R, Sprent J, et al. 2001. IL-7 is critical for homeostatic proliferation and survival of naive T cells. Proc. Natl. Acad. Sci. USA 98:8732-37

14. Maraskovsky E, O'Reilly LA, Teepe M, Corcoran LM, Peschon JJ, Strasser A. 1997. Bcl-2 can rescue T lymphocyte development in interleukin-7 receptor-deficient mice but not in mutant $\mathrm{rag}-1^{-1-}$ mice. Cell 89:1011-19

15. Akashi K, Kondo M, von Freeden-Jeffry U, Murray R, Weissman IL. 1997. Bcl-2 rescues T lymphopoiesis in interleukin-7 receptor-deficient mice. Cell 89:1033-41

16. Rathmell JC, Vander Heiden MG, Harris MH, Frauwirth KA, Thompson CB. 2000. In the absence of extrinsic signals, nutrient utilization by lymphocytes is insufficient to maintain either cell size or viability. Mol. Cell 6:683-92

17. Rathmell JC, Farkash EA, Gao W, Thompson CB. 2001. IL-7 enhances the survival and maintains the size of naive T cells. 7. Immunol. 167:6869-76

18. Barata JT, Silva A, Brandao JG, Nadler LM, Cardoso AA, Boussiotis VA. 2004. Activation of PI3K is indispensable for interleukin 7-mediated viability, proliferation, glucose use, and growth of T cell acute lymphoblastic leukemia cells. 7. Exp. Med. 200:659-69

19. Jacobs SR, Michalek RD, Rathmell JC. 2010. IL-7 is essential for homeostatic control of T cell metabolism in vivo. 7. Immunol. 184:3461-69

20. Pearson C, Silva A, Seddon B. 2012. Exogenous amino acids are essential for interleukin-7 induced CD8 T cell growth. PLoS ONE 7:e33998

21. Jameson SC. 2002. Maintaining the norm: T-cell homeostasis. Nat. Rev. Immunol. 2:547-56

22. Marrack P, Bender J, Hildeman D, Jordan M, Mitchell T, et al. 2000. Homeostasis of $\alpha \beta \mathrm{TCR}^{+} \mathrm{T}$ cells. Nat. Immunol. 1:107-11

23. Jacobs SR, Herman CE, Maciver NJ, Wofford JA, Wieman HL, et al. 2008. Glucose uptake is limiting in T cell activation and requires CD28-mediated Akt-dependent and independent pathways. F. Immunol. 180:4476-86

24. Doughty CA, Bleiman BF, Wagner DJ, Dufort FJ, Mataraza JM, et al. 2006. Antigen receptor-mediated changes in glucose metabolism in B lymphocytes: role of phosphatidylinositol 3-kinase signaling in the glycolytic control of growth. Blood 107:4458-65

25. Greiner EF, Guppy M, Brand K. 1994. Glucose is essential for proliferation and the glycolytic enzyme induction that provokes a transition to glycolytic energy production. F. Biol. Chem. 269:31484-90

26. Bental M, Deutsch C. 1993. Metabolic changes in activated T cells: an NMR study of human peripheral blood lymphocytes. Magn. Reson. Med. 29:317-26

27. Michalek RD, Gerriets VA, Jacobs SR, Macintyre AN, MacIver NJ, et al. 2011. Cutting edge: Distinct glycolytic and lipid oxidative metabolic programs are essential for effector and regulatory $\mathrm{CD} 4^{+} \mathrm{T}$ cell subsets. F. Immunol. 186:3299-303

28. Cham CM, Gajewski TF. 2005. Glucose availability regulates IFN- $\gamma$ production and p70S6 kinase activation in $\mathrm{CD}^{+}$effector T cells. F. Immunol. 174:4670-77

29. Zheng Y, Delgoffe GM, Meyer CF, Chan W, Powell JD. 2009. Anergic T cells are metabolically anergic. 7. Immunol. 183:6095-101

30. Shi LZ, Wang R, Huang G, Vogel P, Neale G, et al. 2011. HIF1 $\alpha$-dependent glycolytic pathway orchestrates a metabolic checkpoint for the differentiation of $\mathrm{T}_{\mathrm{H}} 17$ and $\mathrm{T}_{\mathrm{reg}}$ cells. F. Exp. Med. 208:136776

www.annualreviews.org • T Lymphocyte Metabolism

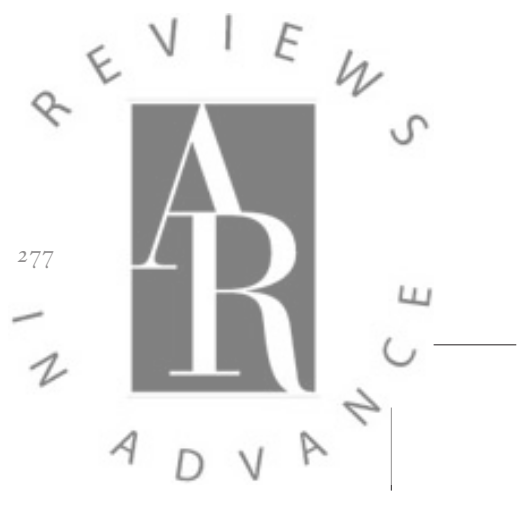


31. Dang CV, Le A, Gao P. 2009. MYC-induced cancer cell energy metabolism and therapeutic opportunities. Clin. Cancer Res. 15:6479-83

32. Gao P, Tchernyshyov I, Chang TC, Lee YS, Kita K, et al. 2009. c-Myc suppression of miR-23a/b enhances mitochondrial glutaminase expression and glutamine metabolism. Nature 458:762-65

33. Wise DR, DeBerardinis RJ, Mancuso A, Sayed N, Zhang XY, et al. 2008. Myc regulates a transcriptional program that stimulates mitochondrial glutaminolysis and leads to glutamine addiction. Proc. Natl. Acad. Sci. USA 105:18782-87

34. Lindsten T, June CH, Thompson CB. 1988. Multiple mechanisms regulate c-myc gene expression during normal $\mathrm{T}$ cell activation. EMBO 7. 7:2787-94

35. Kelly K, Cochran BH, Stiles CD, Leder P. 1983. Cell-specific regulation of the $c$-myc gene by lymphocyte mitogens and platelet-derived growth factor. Cell 35:603-10

36. Wang R, Dillon CP, Shi LZ, Milasta S, Carter R, et al. 2011. The transcription factor Myc controls metabolic reprogramming upon $\mathrm{T}$ lymphocyte activation. Immunity 35:871-82

37. Colombo SL, Palacios-Callender M, Frakich N, De Leon J, Schmitt CA, et al. 2010. Anaphase-promoting complex/cyclosome-Cdh1 coordinates glycolysis and glutaminolysis with transition to $\mathrm{S}$ phase in human T lymphocytes. Proc. Natl. Acad. Sci. USA 107:18868-73

38. Altman BJ, Dang CV. 2012. Normal and cancer cell metabolism: lymphocytes and lymphoma. FEBS 7. 279:2598-609

39. Villena JA, Kralli A. 2008. ERR $\alpha$ : a metabolic function for the oldest orphan. Trends Endocrinol. Metab. 19:269-76

40. Giguère V. 2008. Transcriptional control of energy homeostasis by the estrogen-related receptors. Endocr. Rev. 29:677-96

41. Ranhotra HS. 2010. The estrogen-related receptor alpha: the oldest, yet an energetic orphan with robust biological functions. 7. Recept. Signal. Transduct. Res. 30:193-205

42. Sonoda J, Laganière J, Mehl IR, Barish GD, Chong LW, et al. 2007. Nuclear receptor ERR $\alpha$ and coactivator PGC-1 $\beta$ are effectors of IFN- $\gamma$-induced host defense. Genes Dev. 21:1909-20

43. Luo J, Sladek R, Carrier J, Bader JA, Richard D, Giguère V. 2003. Reduced fat mass in mice lacking orphan nuclear receptor estrogen-related receptor $\alpha$. Mol. Cell. Biol. 23:7947-56

44. Deblois G, Hall JA, Perry MC, Laganière J, Ghahremani M, et al. 2009. Genome-wide identification of direct target genes implicates estrogen-related receptor $\alpha$ as a determinant of breast cancer heterogeneity. Cancer Res. 69:6149-57

45. Jarzabek K, Koda M, Kozlowski L, Sulkowski S, Kottler ML, Wolczynski S. 2009. The significance of the expression of ERR $\alpha$ as a potential biomarker in breast cancer. F. Steroid Biochem. Mol. Biol. 113:127-33

46. Chisamore MJ, Wilkinson HA, Flores O, Chen JD. 2009. Estrogen-related receptor- $\alpha$ antagonist inhibits both estrogen receptor-positive and estrogen receptor-negative breast tumor growth in mouse xenografts. Mol. Cancer Ther. 8:672-81

47. Stein RA, Chang CY, Kazmin DA, Way J, Schroeder T, et al. 2008. Estrogen-related receptor $\alpha$ is critical for the growth of estrogen receptor-negative breast cancer. Cancer Res. 68:8805-12

48. Tennessen JM, Baker KD, Lam G, Evans J, Thummel CS. 2011. The Drosophila estrogen-related receptor directs a metabolic switch that supports developmental growth. Cell Metab. 13:139-48

49. Perry DJ, Yin Y, Telarico T, Baker HV, Dozmorov I, et al. 2012. Murine lupus susceptibility locus Sle 1c2 mediates $\mathrm{CD}^{+}{ }^{+} \mathrm{T}$ cell activation and maps to estrogen-related receptor $\gamma \cdot \mathcal{F}$. Immunol. 189:793-803

50. Michalek RD, Gerriets VA, Nichols AG, Inoue M, Kazmin D, et al. 2011. Estrogen-related receptor$\alpha$ is a metabolic regulator of effector T-cell activation and differentiation. Proc. Natl. Acad. Sci. USA 108:18348-53

51. Bensinger SJ, Bradley MN, Joseph SB, Zelcer N, Janssen EM, et al. 2008. LXR signaling couples sterol metabolism to proliferation in the acquired immune response. Cell 134:97-111

52. Xu J, Wagoner G, Douglas JC, Drew PD. 2009. Liver X receptor agonist regulation of Th17 lymphocyte function in autoimmunity. F. Leukoc. Biol. 86:401-9

53. Cui G, Qin X, Wu L, Zhang Y, Sheng X, et al. 2011. Liver X receptor (LXR) mediates negative regulation of mouse and human Th17 differentiation. F. Clin. Investig. 121:658-70

54. Frauwirth KA, Riley JL, Harris MH, Parry RV, Rathmell JC, et al. 2002. The CD28 signaling pathway regulates glucose metabolism. Immunity 16:769-77

MacIver • Michalek • Rathmell 
55. Rathmell JC, Fox CJ, Plas DR, Hammerman PS, Cinalli RM, Thompson CB. 2003. Akt-directed glucose metabolism can prevent Bax conformation change and promote growth factor-independent survival. Mol. Cell. Biol. 23:7315-28

56. Edinger AL, Thompson CB. 2002. Akt maintains cell size and survival by increasing mTOR-dependent nutrient uptake. Mol. Biol. Cell 13:2276-88

57. Edinger AL. 2007. Controlling cell growth and survival through regulated nutrient transporter expression. Biochem. 7. 406:1-12

58. Zhou QL, Jiang ZY, Holik J, Chawla A, Hagan GN, et al. 2008. Akt substrate TBC1D1 regulates GLUT1 expression through the mTOR pathway in 3T3-L1 adipocytes. Biochem. 7. 411:647-55

59. Wieman HL, Wofford JA, Rathmell JC. 2007. Cytokine stimulation promotes glucose uptake via phosphatidylinositol-3 kinase/Akt regulation of Glut1 activity and trafficking. Mol. Biol. Cell 18:1437-46

60. Edinger AL, Cinalli RM, Thompson CB. 2003. Rab7 prevents growth factor-independent survival by inhibiting cell-autonomous nutrient transporter expression. Dev. Cell 5:571-82

61. Wieman HL, Horn SR, Jacobs SR, Altman BJ, Kornbluth S, Rathmell JC. 2009. An essential role for the Glut1 PDZ-binding motif in growth factor regulation of Glut1 degradation and trafficking. Biochem. 7. 418:345-67

62. Miyamoto S, Murphy AN, Brown JH. 2008. Akt mediates mitochondrial protection in cardiomyocytes through phosphorylation of mitochondrial hexokinase-II. Cell Death Differ. 15:521-29

63. John S, Weiss JN, Ribalet B. 2011. Subcellular localization of hexokinases I and II directs the metabolic fate of glucose. PLoS ONE 6:e17674

64. Chi H. 2012. Regulation and function of mTOR signalling in T cell fate decisions. Nat. Rev. Immunol. $12: 325-38$

65. Tandon P, Gallo CA, Khatri S, Barger JF, Yepiskoposyan H, Plas DR. 2011. Requirement for ribosomal protein S6 kinase 1 to mediate glycolysis and apoptosis resistance induced by Pten deficiency. Proc. Natl. Acad. Sci. USA 108:2361-65

66. Porstmann T, Santos CR, Griffiths B, Cully M, Wu M, et al. 2008. SREBP activity is regulated by mTORC1 and contributes to Akt-dependent cell growth. Cell Metab. 8:224-36

67. Deberardinis RJ, Lum JJ, Thompson CB. 2006. Phosphatidylinositol 3-kinase-dependent modulation of carnitine palmitoyltransferase $1 \mathrm{~A}$ expression regulates lipid metabolism during hematopoietic cell growth. 7. Biol. Chem. 281:37372-80

68. Powell JD, Delgoffe GM. 2010. The mammalian target of rapamycin: linking $T$ cell differentiation, function, and metabolism. Immunity 33:301-11

69. Hardie DG. 2007. AMP-activated/SNF1 protein kinases: conserved guardians of cellular energy. Nat. Rev. Mol. Cell Biol. 8:774-85

70. Tamas P, Hawley SA, Clarke RG, Mustard KJ, Green K, et al. 2006. Regulation of the energy sensor AMP-activated protein kinase by antigen receptor and $\mathrm{Ca}^{2+}$ in T lymphocytes. F. Exp. Med. 203:1665-70

71. Hemminki A, Markie D, Tomlinson I, Avizienyte E, Roth S, et al. 1998. A serine/threonine kinase gene defective in Peutz-Jeghers syndrome. Nature 391:184-87

72. Jenne DE, Reimann H, Nezu J, Friedel W, Loff S, et al. 1998. Peutz-Jeghers syndrome is caused by mutations in a novel serine threonine kinase. Nat. Genet. 18:38-43

73. Shaw RJ, Kosmatka M, Bardeesy N, Hurley RL, Witters LA, et al. 2004. The tumor suppressor LKB1 kinase directly activates AMP-activated kinase and regulates apoptosis in response to energy stress. Proc. Natl. Acad. Sci. USA 101:3329-35

74. Hawley SA, Boudeau J, Reid JL, Mustard KJ, Udd L, et al. 2003. Complexes between the LKB1 tumor suppressor, STRAD $\alpha / \beta$ and MO25 $\alpha / \beta$ are upstream kinases in the AMP-activated protein kinase cascade. 7. Biol. 2:28

75. Woods A, Johnstone SR, Dickerson K, Leiper FC, Fryer LG, et al. 2003. LKB1 is the upstream kinase in the AMP-activated protein kinase cascade. Curr. Biol. 13:2004-8

76. Cao Y, Li H, Liu H, Zheng C, Ji H, Liu X. 2010. The serine/threonine kinase LKB1 controls thymocyte survival through regulation of AMPK activation and Bcl-XL expression. Cell Res. 20:99-108

77. Tamás P, Macintyre A, Finlay D, Clarke R, Feijoo-Carnero C, et al. 2010. LKB1 is essential for the proliferation of T-cell progenitors and mature peripheral T cells. Eur. F. Immunol. 40:242-53

www.annualreviews.org • T Lymphocyte Metabolism

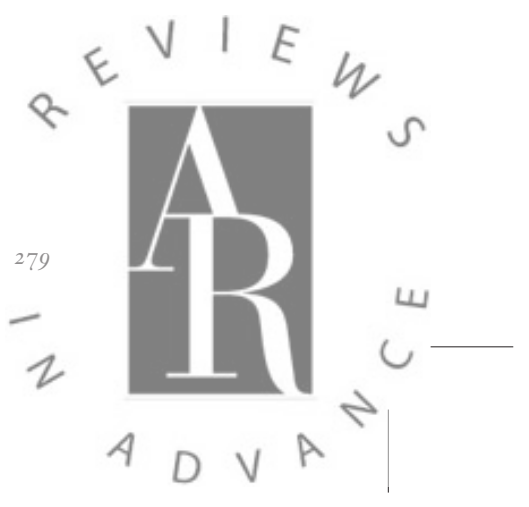


78. MacIver NJ, Blagih J, Saucillo DC, Tonelli L, Griss T, et al. 2011. The liver kinase B1 is a central regulator of $\mathrm{T}$ cell development, activation, and metabolism. F. Immunol. 187:4187-98

79. Alers S, Löffler AS, Wesselborg S, Stork B. 2012. Role of AMPK-mTOR-Ulk1/2 in the regulation of autophagy: cross talk, shortcuts, and feedbacks. Mol. Cell. Biol. 32:2-11

80. Pua HH, He YW. 2007. Maintaining T lymphocyte homeostasis: another duty of autophagy. Autophagy $3: 266-67$

81. Hubbard VM, Valdor R, Patel B, Singh R, Cuervo AM, Macian F. 2010. Macroautophagy regulates energy metabolism during effector T cell activation. 7. Immunol. 185:7349-57

82. Michalek RD, Rathmell JC. 2010. The metabolic life and times of a T-cell. Immunol. Rev. 236:190-202

83. Zheng Y, Collins SL, Lutz MA, Allen AN, Kole TP, et al. 2007. A role for mammalian target of rapamycin in regulating T cell activation versus anergy. F. Immunol. 178:2163-70

84. Kopf H, de la Rosa GM, Howard OM, Chen X. 2007. Rapamycin inhibits differentiation of Th17 cells and promotes generation of FoxP3 ${ }^{+} \mathrm{T}$ regulatory cells. Int. Immunopharmacol. 7:1819-24

85. Delgoffe GM, Kole TP, Zheng Y, Zarek PE, Matthews KL, et al. 2009. The mTOR kinase differentially regulates effector and regulatory T cell lineage commitment. Immunity 30:832-44

86. Delgoffe GM, Pollizzi KN, Waickman AT, Heikamp E, Meyers DJ, et al. 2011. The kinase mTOR regulates the differentiation of helper $\mathrm{T}$ cells through the selective activation of signaling by mTORC1 and mTORC2. Nat. Immunol. 12:295-303

87. Cobbold SP, Adams E, Farquhar CA, Nolan KF, Howie D, et al. 2009. Infectious tolerance via the consumption of essential amino acids and mTOR signaling. Proc. Natl. Acad. Sci. USA 106:12055-60

88. Yan Z, Garg SK, Banerjee R. 2010. Regulatory T cells interfere with glutathione metabolism in dendritic cells and T cells. F. Biol. Chem. 285:41525-32

89. Semenza GL. 2007. Hypoxia-inducible factor 1 (HIF-1) pathway. Sci. STKE 2007:cm8

90. Dang EV, Barbi J, Yang HY, Jinasena D, Yu H, et al. 2011. Control of $\mathrm{T}_{\mathrm{H}} 17 / \mathrm{T}_{\text {reg }}$ balance by hypoxiainducible factor 1. Cell 146:772-84

91. He S, Kato K, Jiang J, Wahl DR, Mineishi S, et al. 2011. Characterization of the metabolic phenotype of rapamycin-treated $\mathrm{CD} 8^{+} \mathrm{T}$ cells with augmented ability to generate long-lasting memory cells. PLoS ONE 6:e20107

92. Araki K, Turner AP, Shaffer VO, Gangappa S, Keller SA, et al. 2009. mTOR regulates memory CD8 T-cell differentiation. Nature 460:108-12

93. Pearce EL, Walsh MC, Cejas PJ, Harms GM, Shen H, et al. 2009. Enhancing CD8 T-cell memory by modulating fatty acid metabolism. Nature 460:103-7

94. Lee NK, Lee SY. 2002. Modulation of life and death by the tumor necrosis factor receptor-associated factors (TRAFs). F. Biochem. Mol. Biol. 35:61-66

95. van der Windt GJW, Everts B, Chang CH, Curtis JD, Freitas TC, et al. 2012. Mitochondrial respiratory capacity is a critical regulator of $\mathrm{CD} 8^{+} \mathrm{T}$ cell memory development. Immunity 36:68-78

96. Schwartz RH. 2003. T cell anergy. Annu. Rev. Immunol. 21:305-34

97. Harding FA, McArthur JG, Gross JA, Raulet DH, Allison JP. 1992. CD28-mediated signalling costimulates murine T cells and prevents induction of anergy in T-cell clones. Nature 356:607-9

98. Powell JD, Lerner CG, Schwartz RH. 1999. Inhibition of cell cycle progression by rapamycin induces T cell clonal anergy even in the presence of costimulation. F. Immunol. 162:2775-84

99. Tokunaga C, Yoshino K, Yonezawa K. 2004. mTOR integrates amino acid- and energy-sensing pathways. Biochem. Biophys. Res. Commun. 313:443-46

100. Beverly B, Kang SM, Lenardo MJ, Schwartz RH. 1992. Reversal of in vitro T cell clonal anergy by IL-2 stimulation. Int. Immunol. 4:661-71

101. Zajac AJ, Blattman JN, Murali-Krishna K, Sourdive DJ, Suresh M, et al. 1998. Viral immune evasion due to persistence of activated T cells without effector function. F. Exp. Med. 188:2205-13

102. Shin H, Wherry EJ. 2007. CD8 T cell dysfunction during chronic viral infection. Curr. Opin. Immunol. 19:408-15

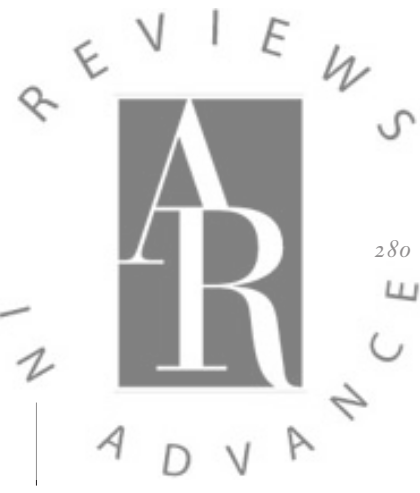

03. Wherry EJ, Ha SJ, Kaech SM, Haining WN, Sarkar S, et al. 2007. Molecular signature of CD8 ${ }^{+}$T cell exhaustion during chronic viral infection. Immunity 27:670-84

104. Barber DL, Wherry EJ, Masopust D, Zhu B, Allison JP, et al. 2006. Restoring function in exhausted CD8 T cells during chronic viral infection. Nature 439:682-87 
105. Kaufmann DE, Walker BD. 2009. PD-1 and CTLA-4 inhibitory cosignaling pathways in HIV infection and the potential for therapeutic intervention. F. Immunol. 182:5891-97

106. Blackburn SD, Shin H, Haining WN, Zou T, Workman CJ, et al. 2009. Coregulation of CD8 ${ }^{+} \mathrm{T}$ cell exhaustion by multiple inhibitory receptors during chronic viral infection. Nat. Immunol. 10:29-37

107. Parry RV, Chemnitz JM, Frauwirth KA, Lanfranco AR, Braunstein I, et al. 2005. CTLA-4 and PD-1 receptors inhibit T-cell activation by distinct mechanisms. Mol. Cell. Biol. 25:9543-53

108. Francisco LM, Salinas VH, Brown KE, Vanguri VK, Freeman GJ, et al. 2009. PD-L1 regulates the development, maintenance, and function of induced regulatory T cells. F. Exp. Med. 206:3015-29

109. Weng NP, Akbar AN, Goronzy J. 2009. CD28 ${ }^{-}$T cells: their role in the age-associated decline of immune function. Trends Immunol. 30:306-12

110. Coloff JL, Mason EF, Altman BJ, Gerriets VA, Liu T, et al. 2011. Akt requires glucose metabolism to suppress puma expression and prevent apoptosis of leukemic T cells. F. Biol. Chem. 286:5921-33

111. Navarro F, Bacurau AVN, Vanzelli A, Meneguello-Coutinho M, Uchida MC, et al. 2010. Changes in glucose and glutamine lymphocyte metabolisms induced by type I interferon $\alpha$. Mediat. Inflamm. 2010:364290

112. Ostroukhova M, Goplen N, Karim MZ, Michalec L, Guo L, et al. 2012. The role of low-level lactate production in airway inflammation in asthma. Am. 7. Physiol. Lung Cell Mol. Physiol. 302:L300-7

113. Bian L, Josefsson E, Jonsson IM, Verdrengh M, Ohlsson C, et al. 2009. Dichloroacetate alleviates development of collagen II-induced arthritis in female DBA/1 mice. Arthritis Res. Ther. 11:R132

114. Benke PJ, Drisko J, Ahmad P. 1991. Increased oxidative metabolism in phytohemagglutinin-stimulated lymphocytes from patients with systemic lupus erythematosus is associated with serum SSA antibody. Biochem. Med. Metab. Biol. 45:28-40

115. Nagy G, Koncz A, Perl A. 2005. T- and B-cell abnormalities in systemic lupus erythematosus. Crit. Rev. Immunol. 25:123-40

116. Gergely P Jr, Grossman C, Niland B, Puskas F, Neupane H, et al. 2002. Mitochondrial hyperpolarization and ATP depletion in patients with systemic lupus erythematosus. Arthritis Rheum. 46:175-90

117. Wahl DR, Petersen B, Warner R, Richardson BC, Glick GD, Opipari AW. 2010. Characterization of the metabolic phenotype of chronically activated lymphocytes. Lupus 19:1492-501

118. Johnson KM, Chen X, Boitano A, Swenson L, Opipari AW, Glick GD. 2005. Identification and validation of the mitochondrial $\mathrm{F}_{1} \mathrm{~F}_{0}$-ATPase as the molecular target of the immunomodulatory benzodiazepine Bz-423. Chem. Biol. 12:485-96

119. Gatza E, Wahl DR, Opipari AW, Sundberg TB, Reddy P, et al. 2011. Manipulating the bioenergetics of alloreactive T cells causes their selective apoptosis and arrests graft-versus-host disease. Sci. Transl. Med. 3:67ra8

120. Miesel R, Murphy MP, Kroger H. 1996. Enhanced mitochondrial radical production in patients which rheumatoid arthritis correlates with elevated levels of tumor necrosis factor $\alpha$ in plasma. Free Radic. Res. 25:161-69

121. Biniecka M, Fox E, Gao W, Ng CT, Veale DJ, et al. 2011. Hypoxia induces mitochondrial mutagenesis and dysfunction in inflammatory arthritis. Artbritis Rheum. 63:2172-82

122. Harty LC, Biniecka M, O'Sullivan J, Fox E, Mulhall K, et al. 2012. Mitochondrial mutagenesis correlates with the local inflammatory environment in arthritis. Ann. Rheum. Dis. 71:582-88

123. Kopp HP, Kopp CW, Festa A, Krzyzanowska K, Kriwanek S, et al. 2003. Impact of weight loss on inflammatory proteins and their association with the insulin resistance syndrome in morbidly obese patients. Arterioscler. Thromb. Vasc. Biol. 23:1042-47

124. Hotamisligil GS, Shargill NS, Spiegelman BM. 1993. Adipose expression of tumor necrosis factor- $\alpha$ : direct role in obesity-linked insulin resistance. Science 259:87-91

125. Uysal KT, Wiesbrock SM, Marino MW, Hotamisligil GS. 1997. Protection from obesity-induced insulin resistance in mice lacking TNF- $\alpha$ function. Nature 389:610-14

126. Ventre J, Doebber T, Wu M, MacNaul K, Stevens K, et al. 1997. Targeted disruption of the tumor necrosis factor- $\alpha$ gene: metabolic consequences in obese and nonobese mice. Diabetes 46:1526-31

127. Krogh-Madsen R, Plomgaard P, Moller K, Mittendorfer B, Pedersen BK. 2006. Influence of TNF- $\alpha$ and IL-6 infusions on insulin sensitivity and expression of IL-18 in humans. Am. 7. Physiol. Endocrinol. Metab. 291:E108-14

www.annualreviews.org • T Lymphocyte Metabolism

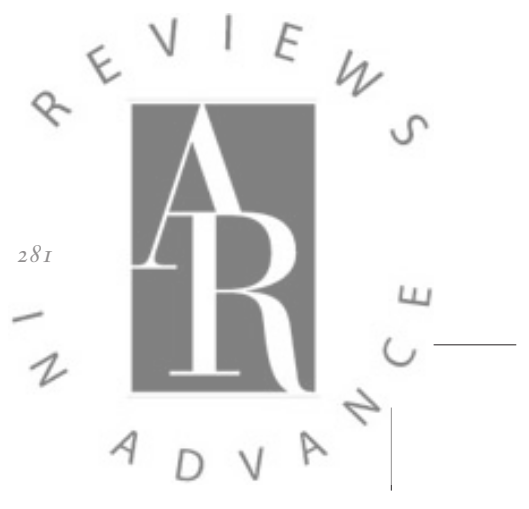


128. Gregor MF, Hotamisligil GS. 2011. Inflammatory mechanisms in obesity. Annu. Rev. Immunol. 29:41545

129. Ouchi N, Parker JL, Lugus JJ, Walsh K. 2011. Adipokines in inflammation and metabolic disease. Nat. Rev. Immunol. 11:85-97

130. Olefsky JM, Glass CK. 2010. Macrophages, inflammation, and insulin resistance. Annu. Rev. Physiol. 72:219-46

131. Galic S, Oakhill JS, Steinberg GR. 2010. Adipose tissue as an endocrine organ. Mol. Cell. Endocrinol. 316:129-39

132. Vats D, Mukundan L, Odegaard JI, Zhang L, Smith KL, et al. 2006. Oxidative metabolism and PGC-1 $\beta$ attenuate macrophage-mediated inflammation. Cell Metab. 4:13-24

133. Nishimura S, Manabe I, Nagasaki M, Eto K, Yamashita H, et al. 2009. CD8 ${ }^{+}$effector T cells contribute to macrophage recruitment and adipose tissue inflammation in obesity. Nat. Med. 15:914-20

134. Winer S, Chan Y, Paltser G, Truong D, Tsui H, et al. 2009. Normalization of obesity-associated insulin resistance through immunotherapy. Nat. Med. 15:921-29

135. Feuerer M, Herrero L, Cipolletta D, Naaz A, Wong J, et al. 2009. Lean, but not obese, fat is enriched for a unique population of regulatory T cells that affect metabolic parameters. Nat. Med. 15:930-39

136. Cipolletta D, Feuerer M, Li A, Kamei N, Lee J, et al. 2012. PPAR- $\gamma$ is a major driver of the accumulation and phenotype of adipose tissue $\mathrm{T}_{\text {reg }}$ cells. Nature 486:549-53

137. Ahmed M, Gaffen SL. 2010. IL-17 in obesity and adipogenesis. Cytokine Growth Factor Rev. 21:449-53

138. Zuniga LA, Shen WJ, Joyce-Shaikh B, Pyatnova EA, Richards AG, et al. 2010. IL-17 regulates adipogenesis, glucose homeostasis, and obesity. 7. Immunol. 185:6947-59

139. Mantzoros CS, Magkos F, Brinkoetter M, Sienkiewicz E, Dardeno TA, et al. 2011. Leptin in human physiology and pathophysiology. Am. 7. Physiol. Endocrinol. Metab. 301:E567-84

140. Procaccini C, Jirillo E, Matarese G. 2012. Leptin as an immunomodulator. Mol. Aspects Med. 33:35-45

141. Fernández-Riejos P, Najib S, Santos-Alvarez J, Martín-Romero C, Pérez-Pérez A, et al. 2010. Role of leptin in the activation of immune cells. Mediat. Inflamm. 2010:568343

142. Matarese G, Moschos S, Mantzoros CS. 2005. Leptin in immunology. F. Immunol. 174:3137-42

143. Martín-Romero C, Sánchez-Margalet V. 2001. Human leptin activates PI3K and MAPK pathways in human peripheral blood mononuclear cells: possible role of Sam68. Cell. Immunol. 212:83-91

144. Sánchez-Margalet V, Martín-Romero C. 2001. Human leptin signaling in human peripheral blood mononuclear cells: activation of the JAK-STAT pathway. Cell. Immunol. 211:30-36

145. Chandra RK. 1980. Cell-mediated immunity in genetically obese (C57BL/6J ob/ob) mice. Am. F. Clin. Nutr. 33:13-16

146. Mandel MA, Mahmoud AAF. 1978. Impairment of cell-mediated immunity in mutation diabetic mice (db/db). F. Immunol. 120:1375-77

147. Ozata M, Ozdemir IC, Licinio J. 1999. Human leptin deficiency caused by a missense mutation: Multiple endocrine defects, decreased sympathetic tone, and immune system dysfunction indicate new targets for leptin action, greater central than peripheral resistance to the effects of leptin, and spontaneous correction of leptin-mediated defects. F. Clin. Endocrinol. Metab. 84:3686-95

148. Farooqi IS, Matarese G, Lord GM, Keogh JM, Lawrence E, et al. 2002. Beneficial effects of leptin on obesity, T cell hyporesponsiveness, and neuroendocrine/metabolic dysfunction of human congenital leptin deficiency. 7. Clin. Investig. 110:1093-103

149. Procaccini C, De Rosa V, Galgani M, Abanni L, Cali G, et al. 2010. An oscillatory switch in mTOR kinase activity sets regulatory $\mathrm{T}$ cell responsiveness. Immunity 33:929-41

150. Neumann CG, Gewa C, Bwibo NO. 2004. Child nutrition in developing countries. Pediatr. Ann. 33:65874

151. Brown KH, Solomons NW. 1991. Nutritional problems of developing countries. Infect. Dis. Clin. North Am. 5:297-317

152. Schlaudecker EP, Steinhoff MC, Moore SR. 2011. Interactions of diarrhea, pneumonia, and malnutrition in childhood: recent evidence from developing countries. Curr. Opin. Infect. Dis. 24:496-502

153. Rodríguez L, Graniel J, Ortiz R. 2007. Effect of leptin on activation and cytokine synthesis in peripheral blood lymphocytes of malnourished infected children. Clin. Exp. Immunol. 148:478-85 
154. Altman BJ, Jacobs SR, Mason EF, Michalek RD, MacIntyre AN, et al. 2011. Autophagy is essential to suppress cell stress and to allow BCR-Abl-mediated leukemogenesis. Oncogene 30:1855-67

155. Li C, Capan E, Zhao Y, Zhao J, Stolz D, et al. 2006. Autophagy is induced in CD4 ${ }^{+}$T cells and important for the growth factor-withdrawal cell death. F. Immunol. 177:5163-68

156. Pua HH, Guo J, Komatsu M, He YW. 2009. Autophagy is essential for mitochondrial clearance in mature T lymphocytes. F. Immunol. 182:4046-55

157. Kasai M, Tanida I, Ueno T, Kominami E, Seki S, et al. 2009. Autophagic compartments gain access to the MHC class II compartments in thymic epithelium. F. Immunol. 183:7278-85

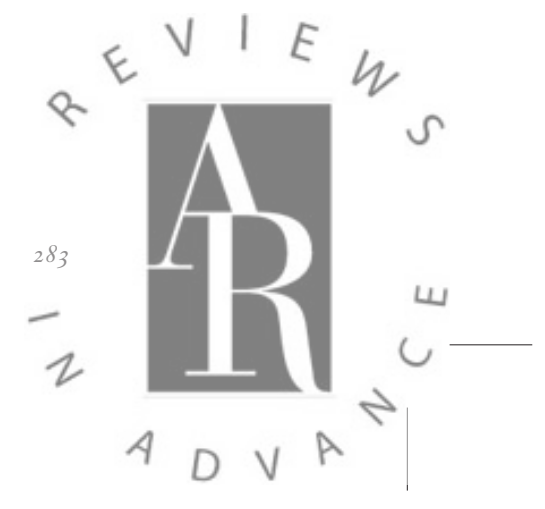

